\title{
DOCUMENTACIÓN DEL FONDO DE OSEIRA (AHN) RELACIONADA CON EL MONASTERIO SAN PEDRO DE VILANOVA DE DOZÓN
}

\section{(1015-1295)}

\author{
Por \\ MIGUEL ROMANÍ MARTÍNEZ \\ PABLO S. OTERO PIÑEYRO MASEDA
}

\section{RESUMEN}

Tras la introducción y criterios de transcripción, se editan 25 documentos de los siglos XI, XII y XIII pertenecientes al fondo de Oseira del AHN relacionados con el monasterio de San Pedro de Vilanova de Dozón, en Tierra de Deza (Pontevedra). Las fechas propuestas permiten observar el paso de la escritura visigótica a la carolina. Se incluye un apéndice con tablas de análisis diplomático y paleográfico, una muestra de las escrituras más representativas, índices onomástico y toponímico, y bibliografía.

\section{PALABRAS CLAVE}

Paleografía, Diplomática, Monasterio. 


\begin{abstract}
After the introduction and the criteria for transcription, we publish 25 documents of the $11^{\text {th }}, 12^{\text {th }}$ and $13^{\text {th }}$ centuries belonging to the collection of Oseira at the AHN related to the monastery of San Pedro de Vilanova de Dozón, in Tierra de Deza (Pontevedra). The suggested periods make it possible to observe the transition from the Visigothic writing to the Carolingian. We also include an appendix with tables of diplomatic and paleographic analyses, a sample of the most representative writings, onomastic and toponymic indices, and a bibliography.
\end{abstract}

\title{
KEYWORDS
}

Paleography, Diplomatics, Monastery.

El monasterio femenino de San Pedro de Vilanova de Dozón fue objeto de un interesante trabajo publicado a fines de los sesenta por don Emilio Duro Peña ${ }^{1}$, que incluía un pequeño, y aleatorio apéndice documental. Posteriormente, el Sr. Fernández añadíria unas notas referentes a las diversas problemáticas que presentaba la fecha de fundación de este cenobio ${ }^{2}$.

Ahora se sacan a la luz veinticinco documentos ${ }^{3}$ de los siglos XI, XII y XIII pertenecientes al fondo del monasterio de Oseira obrante en el Archivo Histórico Nacional que, en su momento, por razones desafortunadas, no pudieron incluirse, como sería lógico, en la Colección Diplomática ursariense $\mathrm{e}^{4}$.

${ }^{1}$ DURO PEÑA, E., El monasterio de San Pedro de Vilanova de Dozón, Archivos Leoneses, 43, año XXII, (enero-junio 1968), pp. 7-62.

${ }^{2}$ FERNÁNDEZ DE VIANA Y VIEITES, J. I., Problemas en torno al monasterio de San Pedro de Dozón, CEG, $X X X V$, (1984-85), pp. 117-123.

${ }^{3}$ Cierto número de los documentos publicados no guardan relación aparente con el monasterio de Vilanova, sin embargo, y de acuerdo con el Sr. Fernández, puede aceptarse que estos documentos representan propiedades que pasaron a la propiedad del citado monasterio mediante la simple entrega por parte de los cesionistas de los documentos que acreditaban la propiedad del bien cedido. Véase p. 118 de FERNÁNDEZ...

${ }^{4}$ ROMANÍ MARTÍNEZ, M., Colección Diplomática do Mosteiro Cisterciense de Sta. María de Oseira (Ourense), 1025-1310, 2 vols., Santiago, Tórculo, 1989.

«CUADERNOS DE ESTUDIOS GALLEGOS», Tomo L, Fascículo 116, Santiago 2003. 
La presencia de escrituras de Vilanova en el fondo de Oseira no debe atribuirse al desorden sufrido por el traslado de los documentos a Madrid cuando la desamortización: es posible que ambos monasterios tuviesen alguna relación, debido quizá a la coincidencia geográfica de sus bienes ${ }^{5}$, lo cual se demuestra con la presencia de diversas escrituras de Vilanova en el Repertorio de Oseira de finales del S. XVII ${ }^{6}$; asimismo, el hecho de que Guntroda Suárez, la futura fundadora del monasterio de Vilanova, figure en el año 1137 entre los confirmantes del documento fundacional de Oseira no hace más que abundar en las posibles relaciones existentes entre ambos monasterios ${ }^{7}$. Otra prueba más sería el hecho de que el abad de Oseira don fray Suero de Oca (1485-1513) hubiera tomado en 1509 la encomienda del coto de Dozón con su monasterio ${ }^{8}$.

Las instalaciones que compondrían el monasterio de San Pedro de Vilanova de Dozón no han llegado hasta nuestros dias: sólo pervive su bella iglesia románica, hoy la parroquial de Santa María de Dozón, antes denominada de San Pedro do Mosteiro9 ${ }^{9}$. El recuerdo del edificio monástico se conserva, sin embargo, en la existencia del topónimo $O$

\footnotetext{
${ }^{5}$ La mayordomía ursariense de «Lalín y Deza» es un ejemplo, pues sus bienes se extienden por toda la comarca del noreste pontevedrés; v. pp. 93-102 en PORTELA, Ma J.; GARRIDO, M.; ROMANÍ, M., Repertorio para las escripturas del Archivo Bajo. Catálogo del Archivo Monacal de Oseira en 1629, [Santiago], Tórculo, D.L. 1993.Además, los bienes del monasterio de Vilanova se entremezclaban con los de Oseira en otras zonas de las provincias de Orense y Pontevedra: v. a estos efectos la voz Vilanova de Dozón, monasterio de San Pedro de, en GRAN ENCICLOPEDIA GALLEGA, T. 30 , p. 86, y también croquis cartográficos en ROMANÍ MARTÍNEZ, M., El monasterio cisterciense de Santa María de Oseira (Ourense): estudio histórico (1137-1310). Santiago de Compostela, 1989.

${ }^{6}$ En efecto, algunos de los documentos publicados por Duro Peña (v. nota 1) se contienen en extracto en el citado Repertorio (v. nota 4): así el doc. $\mathrm{n}^{\circ} 1$ de Duro se corresponde con la p. 93 del Repertorio; $\mathrm{n}^{\circ} 5$, p. $145 ; \mathrm{n}^{\circ} 7$, p. $214 ; \mathrm{n}^{\circ} 8$, p. $93 ; \mathrm{n}^{\circ} 17$, p. 96.- Igualmente, también figuran extractados en el Repertorio algunos documentos editados por M. ROMANÍ MARTÍNEZ en su Colección Diplomática... (v. nota 3): n 262 de la Colección Diplomática, se corresponde con la p. 93 del Repertorio; ${ }^{\circ} 276$, p. $93 ; n^{\circ}$ 1296 , p. 145. Finalmente, los documentos $\mathrm{n}^{\mathrm{os}} .10$ y 17 de este trabajo, figuran extractados en las pp. 57 y 129 , respectivamente, del Repertorio.

${ }^{7}$ Véase la relación de confirmantes en doc. $\mathrm{n}^{\circ} 14$ de La Colección Diplomática.... de ROMANÍ MARTÍNEZ, $M$.

${ }^{8}$ Véase DURO PEÑA, op. cit. pp. 19 y 21.

${ }^{9}$ Véase DURO PEÑA, op. cit. p. 1.
} 
Mosteiro $^{10}$, dentro de la misma parroquia, testimonio toponímico, esta vez sí acertado, del notabilísimo pasado medieval y monástico de este lugar.

El corpus documental de Vilanova es relevante, lo mismo que su dispersión: el Archivo Historico Nacional en sus fondos de Oseira y Vilanova, el Archivo Catedralicio de Orense, el Archivo Provincial de de la misma ciudad y el Archivo de San Pelayo de Antealtares custodian, como mínimo, cerca de 400 documentos contabilizados por el Sr. Fernández, entre documentos originales y copias en extracto.

La importancia de los 25 documentos que ahora se publican radica en que permiten un acercamiento a un espacio y a una sociedad rural, la Tierra de Deza, no muy sobrado en fuentes escritas para esta época. Al mismo tiempo debe señalarse la abundancia de topónimos y microtopónimos mostrada, fundamentalmente, por la documentación de los siglos XI y XII que ha sido reiteradamente ignorada por los organismos y comisiones encargados de elaborar la toponimia oficial gallega ${ }^{11}$.

Los primeros datos de San Pedro de Vilanova se relacionan con su fundadora, doña Guntroda Suárez, o más bien con su familia, como se deduce del aparato documental aquí transcrito ${ }^{12}$. De nuevo, tanto don Emilio Duro como el Sr. Fernández se han ocupado de esclarecer en mayor o menor medida los pasos precedentes a la fundación y su posterior abadologio. Aquí no cabe más que considerar como fecha válida de fundación del monasterio la de 1154, pero sin ser esto óbice para que éste ya vinieşe funcionando como tal desde algunos años antes ${ }^{13}$.

Desde el punto de vista paleográfico, estos documentos ofrecen una interesante visión del campo paleográfico galaico: la tradicional escritura

\footnotetext{
${ }^{10}$ Decreto 219/1998, do 2 de xullo, polo que se aproba o nomenclátor correspondente ás entidades de poboación da provincia de Pontevedra, Diario Oficial de Galicia, Santiago, 28 de Julio de 1998, p. 8541.

${ }^{11}$ Puede comprobarse que en la documentación de los siglos referidos cualquier lugar, monte o accidente geográfico, por mínimo que sea, tiene su nombre: estas fuentes históricas deberían ser pieza clave para la recuperación rigurosa y, en algunas ocasiones, restablecimiento de la toponimia gallega.

${ }^{12}$ Pelagio Martínez, marido de doña Guntroda; su padre Suero Pérez y su madre Teresa Rodríguez; su hermano Pedro Suárez, son entre otros, los personajes más presentes en esta documentación.

${ }^{13}$ Véase como en el doc. núm. 13, de 1151, doña Guntroda ya es denominada «monasterii Sancti Petri de Villa Nova domine atque abbatisse». Se desprende, pues, que antes de la fundación propiamente física del monasterio ya existía una comunidad que demandaba ese edificio.
}

«CUADERNOS DE ESTUDIOS GALLEGOS», Tomo L, Fascículo 116, Santiago 2003. 
visigótica cursiva del antiguo reino astur-leonés se ve ya claramente influenciada y penetrada por la escritura llamada redonda o caligráfica castellana, no siempre bien entendida o asimilada por los amanuenses gallegos.

El fin definitivo del ciclo visigótico en la tierra dezana está representado por diez documentos realizados en la nueva escritura carolina. La transición a la nueva modalidad se percibe todavía en dos documentos que contienen reminiscencias gráficas visigóticas, tal como se expone en la tabla III del apéndice ${ }^{14}$.

En el aspecto diplomático, sólo cabe destacar que la formulación de la mayoría de estos documentos muestra los últimos ejemplos de unos modelos arcaizantes de redacción caracterizados todavía por el uso de invocaciones, salutaciones, preámbulos, fórmulas de espontaneidad, introducción al dispositivo verbal mediante la partícula «ut», complejas frases de entrega y desposesión de los bienes cedidos, que con el tiempo se simplificarán hasta alcanzar a mediados del S. XIII la plena y característica formulación bajomedieval.

\section{CRITERIOS DE TRANSCRIPCIÓN}

Se utilizan las normas habituales sobre abreviaturas y abreviaciones; además, debe tenerse en cuenta lo que sigue:

- Las invocaciones simbólicas se señalan en mayúsculas, seguidas de punto y guión: MAYÚSCULAS.-

- Los signos notariales se señalan en cursiva entre paréntesis (Signum).

- El fin de renglón en el original se indica con «/ «.

- Las frases o palabras escritas entre renglones se transcriben en superíndice en letra normal.

- Las palabras tachadas se ponen entre paréntesis en la transcripción, en letra normal, seguidas de dos puntos y «tachado» en cursiva.

\footnotetext{
${ }^{14}$ Una excelente síntesis de las características gráficas de estos períodos escriptorios en LUCAS ÁLVAREZ, M., «Paleografía gallega. Estado de la cuestión», Anuario de estudios medievales, 21, (1991) pp. 443-451.
}

«CUADERNOS DE ESTUDIOS GALLEGOS», Tomo L, Fascículo 116, Santiago 2003. 
- La restitución cierta de lo escrito cuando hay una laguna en el texto se escribe entre corchetes [ ].

- Lagunas no restituíbles en el texto se indican con puntos suspensivos entre corchetes [...].

- Las grafías aberrantes o destacables se señalan con un (sic), que afecta a la palabra inmediatamente anterior.

- Los caracteres no presentes en el texto, pero indispensables para su sentido se transcriben entre ángulos $<>$.

- Las palabras o frases dudosas se transcriben en cursiva, seguidas de un interrogante: Sartonio?.

- Los nombres de testigos o confirmantes, que en el original van en columnas, se transcriben seguidos, pero separadas por un punto y guión «.- «.

- La intrusión de letras carolinas en texto visigótico -o viceversa-, se indica en la transcripción por medio de cursivas; esta circunstancia también se advierte en la ficha del documento, dentro del apartado de Observaciones.

\section{ABREVIATURAS UTILIZADAS}

Para ofrecer una mayor claridad, y aunque ya sean de sobra conocidas, a continuación se citan las más habituales:

- AC- Archivo Catedralicio.

- AHN- Archivo Histórico Nacional.

- AHP-Archivo Histórico Provincial.

- CD- Colección Diplomática.

- cod.- Códice.

- doc.- documento.

- extr.- extracto.

- fol. o fols.- folio o folios

- $\mathrm{n}^{\mathrm{o}} \mathrm{o} \mathrm{n}^{\mathrm{os}}$.- número o números.

- orig.- original.

- p. o pp.- página o páginas.

- perg.- pergamino.

- v.- véase o véanse.

«CUADERNOS DE ESTUDIOS GALLEGOS», Tomo L, Fascículo 116, Santiago 2003. 
- ...r.- ... recto.

- ...v.- ... vuelto.

La edición de los documentos se complementa con un apéndice en el que, mediante tres tablas, se ofrece sintéticamente una aproximación diplomática (tabla I) y paleográfica (tablas II y III de letra visigótica y de letra carolina, respectivamente) de los documentos aquí transcritos: de esta forma se evitan explicaciones pesadas y repetitivas y se posibilita la comparación de las diferentes características de las piezas documentales.

A continuación, siguen unas muestras en detalle de las escrituras más representativas, indicando el documento al que pertenece cada una.

El apéndice concluye con dos índices: el onomástico, que recoge a las personas susceptibles de interés, ya sea por su cargo, estado, profesión o filiación, y el toponímico, en el cual se exponen alfabéticamente los antiguos topónimos $\mathrm{y}$, siempre que sea posible, su denominación actual.

Sirvan, pues, estas páginas para recuperar no sólo unas fuentes documentales, testigos de nuestra historia del medievo, sino también para sacar a la luz los antiguos nombres del espacio físico en el que nuestros antergos conocían sus dominios, hoy al alcance de todos nosotros.

\section{COLECCIÓN DOCUMENTAL}

1015, febrero, 28 .

Diego Iohannes y su mujer Sancha Muniz venden a Juan Odariz y a su mujer Onega Vermuiz un casal en la villa de Quintana, bajo el monte Mamuna de Cuñarro, en la parroquia de Santa María de Dozón, por 50 sueldos mergulieses $y$ diversos artículos y animales.

MADRID, $A H N, 1513 / 5$, perg., copia simple, latín, minúscula carolina, 320 x $110 \mathrm{~mm}$.

Observaciones: Este doc. necesariamente tiene que ser copia, ya que presenta una letra carolina muy perfecta: este tipo de escritura no se practica en Galicia, por lo menos, hasta el segundo tercio del siglo XII.

«CUADERNOS DE ESTUDIOS GALLEGOS», Tomo L, Fascículo 116, Santiago 2003. 
In Dei nomine. Ego Didacus Iohannis et uxor mea Sancia Muniz et socra mea Marina Petriz a tibi Iohanne Odarici et uxor mea Onega Vermuiz. In Domino Deo eterne salute, / amen. Ideo placuit mihi per bona pacis et voluntas, sana anima et sana mente, que consilio cordis mei, nullus coque gentis imperio, set propria mihi accessit voluntas, ut faceremus / vobis cartulam venditionis sicut et facimus de hereditate nostra propria que habuimus de ganantia subtus monte Mamuna de Cuiarro, decurrente rio Decon, prope aula Sancte Marie / de Dezum; et ipsa hereditate habet iacentia in villa quos vocitant Quintana: uno kasale toto ab integro quantum ad prestandum hominis est per sus terminis et locis antiquis. Damus vobis / ipsa hereditate pro vestro pretio, $\mathrm{L}^{\mathrm{a}}$ solidos de mergulieses et una vacca in XV solidos, et XXV solidos in clavos et in ferraduras, duos porcos et duos carneros in X solidos, duos / lenzos et una manta in X solidos; et in roboratione duas anf[o]ras et duos curdeiros, et una quarta de manteiga, et $\mathrm{X}$ caseos, et $\mathrm{XX}^{\mathrm{i}}$ panes: $\mathrm{X}$ triticos et $\mathrm{X}$ centenos, / que a nobis et vobis bene complacuit; et de precio nichil remansit in debito pro dare, set completum est. Ita ut, de hodie die vel tempore, sedea ipsa hereditate de iuri nostro abrasa et in vestro iure sit tra/dita atque confirmata evuo perhenni et secula cuncta. In Dei nomine habeatis potestatem et faciatis ex ea que vestra fuerit voluntas in temporibus seculorum.

Si quis tamen, quod fieri non credimus, et aliquis homo de pro/pinquis nostris vel de extraneis ad irrumpendum venerit ista kartula, vel nos venerimus, et nos in concilio non octoricemus, quomodo pariamus a vobis Iohanne, vel qui tua voce pulsaverit, ipsa hereditate / duplata vel triplata et ad dominum terre .CCC ${ }^{\text {os }}$. solidos, et sit maledictus et excommunicatus et cum Iuda traditore in inferno dampnatus. Et ista carta semper in robore permaneat.

Facta / kartula venditionis sub die quo eri era . $\mathrm{M}^{\mathrm{a}}$. $\mathrm{L}^{\mathrm{a}}$. III., et quotum quod eri .II ${ }^{\mathrm{e}}$. kalendas marcii.

Qui presentes fuerunt: Froila ts., Adefonsus ts., Herus ts.

Ego Didacus Ihoannis, una cum uxore mea Sancia Muniz et socra mea Marina Petriz, a tibi Iohanne Odarici et uxor tua Onega Vermuiz in hanc kartulam manus nostra roboramus $(++)$.

(Signum) Iohannes Guterrit notui. 
1082, diciembre, 18 .

Sonegildo y su mujer Ledegundia donan a Pedro Osoriz, ahijado de ésta, varias heredades en San Pedro, en Bertosindi y en la villa de Todereo Elías.

MADRID, $A H N, 1508 / 5$, perg., orig., latín, visigótica caligráfica, 77 x $330 \mathrm{~mm}$., borroso el margen derecho.

CHRISTUS.- In Dei nomine. Ego Sonegildo et utxor mea Ledegundia, in Domino et Deo eterna salutem, amen. Ideo plagui nobis bone pacis volumptas ut perfiliamus / et donamus a tivi, meo affiliato Petro Osoriz, filio de Osorio Muniz et filio de Adosinda Pelaiz.

Do ego Sonegildo a tivi mea uxsore Ledegundia mea racione / de ipsa villa qui iace super baselica Sancti Petri, ipso kasale que abeo comparato de Argilo Quisariquiz cum sua exita usque fere in illos [...] cum suo pumare, de ipso in/ticro, VI intigra, et de ipso alio kasale de Susano que abui meo patre Guntino et mea mater Aragunti comparato de avio Strouco, de ipso kasale intigro II $^{\mathrm{a}}$ / intigra, intus et foris per ubi illa potueritis invenire post parte ipso kasale quanto ad omnis a prestitum est; et in alio loco ubi dicent Bertosindi, III ${ }^{\text {es }}$ lareas / intigras que fuisen ianatas per precium de Tita Mirelliz de intigras III intigra davo; et in alio loco in ipsa villa de Todereo Elias, de quanto resona in mea karta, / meio intigro cun suo plantatu: ipso iam dicto, que de super tasxa, dono e duco et perfilio ego Ledegundia meo afiliato Petro Ossoriz una pariter cum viro meo Sonegildo, et contestavi ego Ledegundia ad viro meo / Sonegildo alia tanta villa in Malarici. Aveas tu meo affiliato et quem [...] / volueris ad patre au<t> matre ubi illa potueris dare.

Et qui a inrunpendum veneri vel venerimus, tam filiis quam nectis, de quale fue genero quia / contra nostrum factum parie quanto inquietare vel presunseri in duplo vel triplo post parte ipsius scripture, et unc factum nostrum plena abe ruvore firmiter.

Facta kartula perfiliacionis vel donacionis die tempore XV kalendas ianuarii, era $\mathrm{C} \mathrm{XX}^{\mathrm{a}}$ post millesima.

«CUADERNOS DE ESTUDIOS GALLEGOS», Tomo L, Fascículo 116, Santiago 2003. 
Ledegundia, una pariter cum meo viro Sonegildo, a tivi afiliato meo Petro, una cum amore de tuo patre et meo cunpatre Osorio et cum matre mea Adosinda, quod $/[\ldots .$.$] minamus, manus nostras rovoramus (+)$.

Que ibi fuerunt: Diacu ts., Pelagio ts., Veremuo ts.

Teomondo abas notui.

1084, abril, 27.

El Conde don Rodrigo Ovéquiz y su mujer Toda Gunzálviz dan a Suero Pérez y a su mujer Teresa Rodríguez la villa de Castro por los servicios prestados.

MADRID, $A H N, 1508 / 6$, perg., orig., latín, visigótica caligráfica, $100 \times 300$ mm.

CHRISTUS.- Sub Christi nomine. Comes Rodrigu, prolix Ovequiz, et congungia mea Todda, prolix Gunzalviz, ad tivi / Suario Petriz et ad uxori tue Tareixa (sic) Rodriquiz. Magnum est enim tidulum donacionis quam etciam / nostre largitatis inrunpere. Ideo plagui nobis nunlisque gentis inperio nec suadentis artigulo, set propria / nostra acessi voluntas ut faceremus a tivi et ad uxori tue kartula donacionis de villa mea propria qui nos avemus / de nostra ganacia, quos recepemus nos ipsa villa de Fernando Vimaraz per nostro precio emto et per carta. Et est ipsa villa in territorio / Aliola, subtus monte Lene, prope rivulo Aliola, concurrentem eglesie Sancti Iuliani et loco predicto vogabulo Kastro. Et abuit / ipse Fredenando ipsa villa de pater suo Vimara Gunzalviz et de aviorum suorum, de ipsa villa qui fui de Gunzalvo, / suo quinione intigro quantum ipsi Fredenando Vimaraz ibidem abuit inter fratres vel / eredes suos. Davimus vobis ipsa villa qum quantum a prestandum ominis est, per ubi illa potueritis invenire, per suis terminis et locis / antiquis per ubi illa villa dividet qum alias villas. Davimus tivi illa atque concedimus, et recepimus de te tuo servicio qui ad nobis pro illa / bene complagui; et de precio aput vos nicil remansit in devito, ita ut, de odie die vel tempore, ipsa villa iam nominata de Kastro de iure / sedea arasa et in tuo dominio sedea tradita aque confirmata; faciendi quod volueris, abeas potestatem. Adeatis vos / et omnis posteritas vestras in seculum seculi in perpetim avituri.

«CUADERNOS DE ESTUDIOS GALLEGOS», Tomo L, Fascículo 116, Santiago 2003. 
Et si aliquis omo de parte nostra vel de extranea qui contra / anc donacionis ad inrumpendum venerit, pariat tivi ipsa villa in duplo vel triplo.

Nodum die $\mathrm{V}^{\mathrm{o}}$ kalendas magii, era $\mathrm{I}^{\mathrm{a}} \mathrm{C} X X \mathrm{II}^{\mathrm{a}}$. /

Comes Dei gratia Rodrigu prolix Ovequiz, et eius congungia Todda prolix Gunzalviz, relegentem audivimus ad vobis iam dictos Suario Petriz / et ad uxor tue Tereixa Rodriquiz in hanc donacionis manus nostras $(++)$.

Qui presentes fuerunt: Petrus ts., Pelagiu ts., Olidi ts.

\section{4}

1085, marzo, 29.

Pelayo Velásquiz vende a su hermano Martín Velásquiz y a la mujer de éste, Odrocia Roderíquiz, dos quintas partes de unas heredades en la villa de Arcos.

MADRID, $A H N, 1508 / 7$, perg., orig., latín, visigótica cursiva, 147 x 194 mm.

In Dei nomen. Ego Pelagio Velasqui a tivi germano meo Martino Velasquiz et uxor tue Odrocia Rodo/riquiz, in Domino Deo eternam salutem, amen. Ideo placuit mici per bone pacis voluntas / ut facere vobis ian dictis kartula venditiones et facimus de ereditate mea probia que / abeo de patre meo Velaszo et mater mea Elloni in villa vocitada Arzos. Damus a ti mea / $\mathrm{V}^{\mathrm{a}}$, et alia $\mathrm{V}^{\mathrm{a}}$ de mea germana dona Adosinda, pro que davit ego ad ean mea va de Meisome/menz (sic); et si illa voluerit sua $\mathrm{V}^{\mathrm{a}}$ in Arzos, abeatis vos mea $\mathrm{V}^{\mathrm{a}}$ in Arzos et $\mathrm{V}^{\mathrm{a}}$ in Meisomenz, abeatis vos et omnis prosapie vestre. Concedo vovis II $^{\text {as }} \mathrm{V}^{\mathrm{a}} \mathrm{V}^{\mathrm{a}}$ as (sic) intigras sive de abolencia quo/modo etian et de conparato sive et de contramutato per ubique eam potueritis invenire. Vin/do ad vovis teras cultas vel barbaras, arvores fructuosas vel infrutuosas, fontes, montes, pas/cus, paulibus, soperatos, palatios, kasas, qui $<\mathrm{n}>$ tanas, ortalles, pumares, sautos, devesas, / exitos montium vel recesun. Condo tivi ipsas villas in territorio Deza, conomento Grava, / suctus monte Agona, arogio Togia, per ubi divide con alias vilas; vindo ad vovis / ipsas II ${ }^{\text {as }} \mathrm{V}^{\mathrm{a}} \mathrm{V}^{\mathrm{a}}$, pro que acipio de te in preciun cavalos II $^{\text {os }}$ badios adpreciatos / in CLX solidos, tanto mici bene conplagui; ut de odie die vel tenpore de iuri meo / aberas $<a>$ et in vestro tradita.

«CUADERNOS DE ESTUDIOS GALLEGOS», Tomo L, Fascículo 116, Santiago 2003. 
Et si aliquis omo ad anc cartula ad inr $<$ um $>$ pendo venerit, abeatis / licentia prendere ea dlubrata (sic) vel triplata vel quomo ad vos fuerit meliorata / et vos perpetim abituri.

Facta kartula venditis (sic) IIII $^{\circ}$ kalendas aprilies, era I C XX III ${ }^{a}$. /

Pelagio Velasquiz a tivi Martino Velasquiz et uxor tue, legenten audivi, et / et (sic) mano mea rovoravit (+).

Qui testes fuerunt: Petro ts., Gutier ts., / Freando ts., Pelagio ts., Froila ts.

Veremudo qui notuit.

(Reverso del documento.) Adefonsus abas Sancti Laurenti cf., Fernandus abas $(+)$.

5

1097, agosto, 18.

Alosinda Susmasci, bajo ciertas condiciones, dona Pelagio Martinz una heredad en la villa Toja junto al río del mismo nombre y bajo el monte Laro.

MADRID, $A H N, 1508 / 12$, perg., orig., latín, visigótica caligráfica, 310 x 90 mm.

In Dei nomine. Ego Alosinda Susmasci ad tibi Pelagio Martinz, in Domino Deo eterna salute, amen. Ob inde placuit mici adque convenit / nullis quoque gentis imperio nec suadentis articulo, sed propria nobis accesit voluntas ut facerem ad vobis kartula de hereditate / mea propria que habeo in villa Togia, iusta ribulo Togia, subtus monte Laro, montes, fontes, arbores fructuosas vel $<$ in $>$ fructuosas, / aquas aquarum cum ductibus earum, sedsicas moniarum (sic) et exitus moncium, secessum vel regressum, cum quantum ad prestitum / ominis est, tam intus quam de foris, per suis terminis et locis, ea secundum obtinuerunt parentes, qum quantum compotet inter / meos germanos vel heredes, mea racione ad integrum per ubi ea potueritis invenire; dum vita vixeri non tolla ea / ad illa mullier, et ad obitum suum, lexe ea in manus de ille Pelagio, aut sua voluntas fueri. Et / accepit ipsa hereditate pro que sagavit de illa villa de rege nominatam Qualamis nomine Petro, et era ibi servitiale cum sua / mulier.

«CUADERNOS DE ESTUDIOS GALLEGOS», Tomo L, Fascículo 116, Santiago 2003. 
Facta kartula perpetim habitura quod erit era ${ }^{\mathrm{a}} \mathrm{C} . \mathrm{XXX}$.V et quotum $\mathrm{V}^{\circ} \mathrm{X}^{\circ}$ kalendas september.

Facta / kartula perpetim habitura, quod legentem audivimus, manus nostras rovoravimus $(+)$.

(Signum) Qui presentes fuerunt: Ordonio ts., Veremudo ts.

Suario qui notuit.

\section{6}

1097, agosto, 18.

Onorico Froilaz y sus hermanos venden a Pelayo Martínez la tercera parte de un casal en la villa de Fonteboa por diez sueldos.

MADRID, $A H N, 1508 / 13$, perg., orig., latín, visigótica caligráfica, 246 x 153 mm.

In Dei nomine. Ego Onoricus Froilaz, una pariter cum iermanus suis Petro Froilaz, Pelagio Froilaz, Trodilli Froilaz, Alosinda / Froilaz, Marina Froilaz, ad tibi Pelagio Martiniz, salutem, amen. $\mathrm{O}<\mathrm{b}>$ inde placuit mici adque convenit, nullis quoque / gentis inperio nec suadentis articulo, set propria nobis accesit bone pacis volumptas ut faceremus ad tibi / kartula de hereditate nostra propria que habemus de pater nostro Froilaz Gomez in villa nominata Fonte Bona / territorio Deza, iusta ribulo Toga, arogio Lucenca, quomodo discurit per terminos de ipso vallo, quomodo ex parte / cum Sancta Eulalia de alia pars, usque ad terminos de Merlaim, usque in terminos de Varcena; de alia pars / terminos ad Pena Vitale, et inde per terminos de Fontanelo; et habeo ipsa hereditate de abolo Sabarico. / Damus ad vobis de ipsa hereditate et de ipso casale III ${ }^{\mathrm{a}}$ integra; montes, fontes, arbores fructuosas vel in/fructuosas, aquis aquarum cum ductibus earum, sesicas molinarum, secesum vel regressum cum /quantum ad prestitum est, tam intus quam de foris, per suis terminis et locis, secundum obtinuerunt / parentes. Damus ad vobis ipsa hereditate pro precio que accepimus de vos, de argento solidos X, que / nobis bene conplacuit, ita ut de hodie die et tempore habeatis vos et omni posteritas vestra.

Si quis tamen, / quod fieri non credimus, aliquis homo ad inrunpendum veneri vel venero, tunc pariet tibi ipsa heredita/te dublata vel triplata.

«CUADERNOS DE ESTUDIOS GALLEGOS», Tomo L, Fascículo 116, Santiago 2003. 
Facta kartula era $\mathrm{I}^{\mathrm{a}} \mathrm{C} X X X \mathrm{~V}^{\mathrm{a}}$ et quot $\mathrm{V}^{\circ} \mathrm{X}^{\circ}$ kalendas september; facta / kartula perpetim habitura quod erit facta, evo perhenni per secula cuncta. In hanc kartula / manus nostra rovoravimus (+).

Qui presentes fuerunt: Ordonio ts., Froila ts., Martino ts., Petro ts.

Suario qui notuit (Signum).

1106, noviembre, 5 .

Pelagio Oduriz y Eilon Moniz venden a Logildo Luz y a su mujer Adosinda Martinz la tercera parte de una heredad en Cenamir, bajo el monte Cercio, cerca de la iglesia de de Santiago de Catasós, por diez sueldos.

MADRID, $A H N, 1508 / 18$, perg., orig., latín, visigótica cursiva, 185 x 185 mm.

CHRISTUS.- In Dei nomine. Ego Pellagio Oduriz <et> Eiloni Moniz vobis Logildo Luz / et uxori sua Adosinda Martinz. In Domino Deo, salutem. Plagu mihi aque conveni / nulis quoque gentis inperio nec suagentis artigulo, sed propria nobis accesit bone / pacis voluntas ut facere ad vobis iam dictis textum scriptura et kartula venditionis sicut / et facimus de ereditate nostra propria que adbemus de susseptionum parentum nostrorum. / Et est illa hered $<$ ita $>$ te in loco predicto Cenamir, sutus monte Circitu, prope aulla / Santi Iacobi Apostoli Captasolis; do vobis de illa ered $<\mathrm{i}>$ tate III ${ }^{\mathrm{a}}$ intigra, sibe de advolentia / quomodo et de conparatio, sibe de ganatia quomodo et contramutato, do vobis / casas, quitanas, pumares, linares, exitum vel regresum, cuntis limitibus vel prestationibus / suis per ubitque ea auctinuerunt genitoris nostros; et adcepimus de vos precio $\mathrm{X}^{\mathrm{m}}$ solidos / de dinario valente in plata. Et sit ipsa III $\mathrm{II}^{\mathrm{a}}$ illos solidos $\mathrm{X}$ non valuerit, interque / illo precio in illas alias tertias IIas qui remansas fuerint ipsa $\mathrm{III}^{\mathrm{a}} \mathrm{L}$ solidos valuerit / in ipsos precio qui superius diximus $\mathrm{s}[. ..] \mathrm{r}$ remanea. Ita ut de odie die vel tenpore / sive de iuri nostro adrasa, in vestro iure sit tradita aque confirmata.

Si quis tamen, quos fierit non / credimus de aliquis omo de pars nostra ad inrumpendum venerit vel venerimus, tam propinqui / quam extraneis, paries illa herditate duplata vel triplata et vos perpetim abitura.

«CUADERNOS DE ESTUDIOS GALLEGOS», Tomo L, Fascículo 116, Santiago 2003. 
Facta $\mathrm{k}<\mathrm{a}>\mathrm{rtula}$ venditionis era I $\mathrm{X}^{\mathrm{L}} \mathrm{IIII}^{\mathrm{a}}$, quotum nonas novembris.

Pelagio et Eiloni, / ad tibi Logildu et uxori vestre Adosinda, / in hanc kartula manus nostras rovoravit $/(+)$.

Qui testes fuerunt: Petrus ts., Pellagio ts., Diegu ts.

Vimara notuit (Signum).

1106, diciembre, 28.

Gudesteo y Pedro Veasquiz venden a Pedro Gudesteiz y a su mujer el casal de Fregulfe en Vilamoure, tierra de Abeancos, por cincuenta sueldos.

MADRID, $A H N, 1508 / 19$, perg., orig., latín, visigótica cursiva, 340 x $110 \mathrm{~mm}$.

CHRISTUS.- In Dei nomine. Ego Gudesteo Veasquiz et Petro Veasquiz, vobis Petrus Gudesteiz et coniunx vestra Marina Arias. In Domino, salute. Plaguit nobis atque conveni, nullisque gentis inperio neque suadentis artigulo, / sed propria nobis accessi volumptas ut faceremus vobis kartula venditionis sicut et fecimus de ereditate nostra propria que habemus de abola nostra Eilo Zanitiz et de pater nostro Veasco / vocitata Villa Mauri, territorio Aviancus, subtus monte Lene, iuxta arrogio Raniola et Varazon, sub aula Sancti Stephani, loco predicto illo kasale de Frugulfi. Damus vobis illa / hereditate, kasas et terras et nemora et homnia genera arborum, quantum ad prestitum hominis est in ipsa hereditate per suis terminis antiquis per ubi illa obtinuerunt avii et intercessores nostri / vel obtinere; damus vobis de illa hereditate iam nominata duas $V^{\text {as }}$ et duas quintas, que ille homine que ibi abitat nominato Ramiro Amiquiz et filis suis tantum, nos conpotet inter nostros iermanos / et heredes. Et accepimus de vos precio $L^{a}$ solidos de dinarios tantum nobis bene conplacuit, et de precio aput vos non remansit in debito; ita ut de hodie die et tempore de iure nostro / abrasa et in vestro iure et dominio sit tradita adque confirmata, habeatis vos firmiter et homnis posteritas vestra iuri quieto.

Et si aliquis homo, de nostra parte vel de extranea, qui contra / hanc kartulam ad inrumpendum veneri vel infringere aut temptare volueri, pa-

«CUADERNOS DE ESTUDIOS GALLEGOS», Tomo L, Fascículo 116, Santiago 2003. 
ria vobis illa hereditate dublata et pro conpositionem templi duo talenta auri.

Facta kartula / vendictionis et firmitatis die $\mathrm{V}^{0}$ kalendas ianuarias, era $\mathrm{I}^{\mathrm{A}} \mathrm{C}^{\mathrm{A}} \mathrm{X}^{\mathrm{L}} \mathrm{IIII}^{\mathrm{A}}$.

Nos nominibus in hanc kartula manus nostras.

Qui presentes fuerunt: Pelagio ts., Adefonso ts., Iohane ts. (Signum).

1116, noviembre, 27

Pedro Muniz, su hermana Elvira Muniz y el marido de ésta, Pelayo Sesnandiz, venden a Pedro Goeztez y a su mujer una heredad en Linares, territorio de Abeancos, «iusta aulla Sancti Iacobi». El precio se paga en metálico y en especie.

MADRID, $A H N, 1508 / 20$, perg., orig., latín, visigótica cursiva, 304 x $150 \mathrm{~mm}$.

CHRISTUS.- In Dei nomine. Ego Petro Muninz, una cum iermana mea Elvira Muninz et viro suo Pelagio Sesnandiz, a vobis Petro Goestez et ad vos Marina Arias. In Domino / Deo, eterna salute, amen. Placui nobis, grato animo et prona volumtate, ut faceremus a vobis kartulla vendicionis, sicut et facimus, de hereditate nostra propria / que habemus de abolorum vel de parentorum nostrorum Munio Guncalviz et de iermana sua Eldonca Guncalviz. Et est illa hereditate in territorio Abiancos, in logo predicto / Linares, ibi in illas quintanas maiores, subtus ille kastro, iusta aulla Sancti Iacobi. Damus inde a vobis VIII ${ }^{\mathrm{va}}$ integra, kasas cum suis parietibus, petras moviles vel inmoviles, / arbores fructuosas vel infructuosas, aquis aquarum, sesicas molinarum, terris cultis vel barbaras, exitus moncium, accesu vel recesu, per ubi illa potuerit invenire per suis terminis / et locis antiquis; damus a vobis, pro que accepimus de vos precio $\mathrm{CC}^{\text {tos }}$ morabitinos, $\mathbf{I}^{\circ}$ kavalo bono in octuaginta solidos, $\mathrm{VI}^{\text {es }}$ vakas obtimas in $\mathrm{X}^{\mathrm{L}}$ solidos et LXXX solidos iaqueses, que nobis bene / conplacuit, et de ipso precio aput vos nilchil remansit in debito. Ita ut, de odie die, sic ipsa hereditate de iure nostro abrasa et in vestro iure, dominio sic tradita / aque confirmata; abeatis vos et homnis posteritas vestra iuri quieto secula cunta, amen. 
Si quis tamen, quo fieri non credit, et alliquis homo de nostra parte vel de extranea / qui contra hanc kartulla venditionis ad inrumpendum venerit vel venerimus, que pariamus a vobis vel ad voci vestre illa hereditate dublata vel triplata, et insuper solidos mile / et vobis perpetim abitura.

Facta kartulla vendicionis die quod erit $\mathrm{V}$ kalendas decembras, era $\mathrm{I}^{\mathrm{a}}$ $\mathrm{C}^{\mathrm{a}} \mathrm{L}^{\mathrm{a}}$ IIII ${ }^{\text {ta }}$.

Ego Petro Moninz et iermana mea Elvira Moninz et / viro suo Pelagio Sesnandiz in hoc (sic) kartulla que legentem audivimus $(+)$ manus nostras rovoravimus $(+)$.

Qui presentes fuerunt pro ts.: Pelagio ts. Petro ts. Petro Pelaiz cf., Munio Odariz cf., Arias Eriz cf.

In temporibus illis regnante regina Orraka et filio suo Adefonsus rex / in Legione et in urbis Kastella et in Galecia; / hic, iam dicta, comite Petrus et in Alva et in Besaucos et in Trava; / hic in Monteroso, comite Munius; hic in Saria, comite Roderigus; / hic in Sancti Iacobi, Diagus episcopus; in lucense sedis, Petrus episcopus; in Sancti Antonini, Diagus abba.

Ovecus qui notuit et confirmat (Signum).

1133, noviembre, 29.

(Cuñarro)

Pedro Alfonsiz y su mujer Odrocia Cresconiz, juntamente con sus hijos, venden a Froila Arias y a su mujer Godina Arias una heredad en la villa de San Salvador de la O (Castro) en tierra de Dozón, por un caballo valorado en dos marcos de plata.

MADRID, $A H N, 1509 / 4$, perg., orig., latín, minúscula carolina-diplomática, $266 \mathrm{x}$ $130 \mathrm{~mm}$.

ORENSE, $A C$, extr., Repertorio, p. 57.

In Dei nomine. Ego Petrus Adefonso et Odrozia Cresconiz et filiis nostris Petro Diaz et Arias Diaz et parentibus nostris et allii plures, ad vobis Froia Arias et uxor vestra / Godina Arias. In Domino Deo eternem salutem, amen. Ideo placuit nobis, bone pacis et voluntas, null/us cogentis imperio nec suadentis articulo, set propria nobis accessit bone pacis / et

«CUADERNOS DE ESTUDIOS GALLEGOS», Tomo L, Fascículo 116, Santiago 2003. 
voluntas, ut faceremus ad vobis Froia Arias et uxor vestra Godina Arias carta venditionis sicut et facimus de hereditate nostra propria que comparavit mater nostra de filias de / Petro Diaz. Et est ipsa hereditate in territorio Dezon, subtus monte Honore, concurrente ad ecclesia Sancti Salvatoris, villa predicta $\mathrm{V}^{\mathrm{a}}$ de Honore, cum omnibus adiunctionibus suis; / damus vobis et concedimus kasas, petras, arbores, terras cultas vel incultas, montes, fontes, pratis, pascuis et padulibus, aquis aquarum, sesicas molinarum, exitus montium / et regressum, pro illa mamua de Pulgam et per Petra Erecta, per suis terminis et locis antiquis per ubi dividitur cum alias villas: per terminis de Laquozos, et inde ad carvalios notatos, et fer / in Pena Alva, et inde per illo vallo de Guimaraes, et fer in Pena Nigra, et inde ad illos Banios, et inde ad Valle Scuro, et inde in illa aqua de Kovelo, per ubi illa po/tueritis invenire, sicut superius diximus, usque ad minima rem. Et accepimus de vos in precio uno kavallo apreciato in duos marcos de plata, que ad nobis et vobis / bene complacuit, et de ipso precio apud vos nihil remansit in debitum, set omnia completum est. Ita ut, de hodie die vel tempore, sit de iure nostro abrasa et in vestro iure / vel dominio sit tradita atque confirmata, habeatis vos et omnis posteritas vestra.

Si quis tamen, quod fieri non credo, aliquis homo contra hanc kartam venditionis ad irumpen/dum venerit vel venerimus, tam nos quam filiis nostris, vel de quinque generatio nostra, quomodo pariant ipsa hereditate duplata vel triplata et quantum a vobis fuerit meliorata, / ad vobis Froia Arias vel ad voci vestre.

Era $\cdot M^{\mathrm{a}} \cdot \mathrm{C}^{\mathrm{a}}$. $L X X^{\mathrm{a}}$. $\mathrm{I}^{\mathrm{a}}$. et quotum quod erit $\mathrm{III}^{\circ}$ kalendas decembris.

Ego Petro Afonso et soror mea Odrocia Cresconiz / et Petro Diaz et Arias Diaz et parentibus nostris et alios plures, ad vobis Froia Arias et uxor vestra Gotina Arias, in hac carta vendicionis manus nostras roboramus. /

Ego Froia Arias et uxor mea Godina Arias, una cum filiis meis d[amus supradicta heredit]ate ad illo hospitale pro remedio anime nostre pro victu pauperibus. Et non habeant / in illa hereditate iure hereditario meis filiis, nisi solus Deus.

Ego Froia Afias et uxor mea Gotina Arias in hac carta manus nostras roboramus. I

Qui presentes fuerunt: Petro ts., Munio ts., Roderico ts.

Ihoannes presbiter cf., Pelagio presbiter cf., Gotina Deo vota cf. /

Pelagio qui notuit. 
1137, diciembre, 10.

Eldara Crescóniz y Luzo Arias venden a Guntroda Suárez una heredad en la villa de Meitiriz, en la parroquia de San Miguel, al pie del monte Aural y a orillas del rio Deza, por 30 sueldos.

MADRID, $A H N, 1509 / 8$, perg., orig., latín, visigótica caligráfica, 296 x $80 \mathrm{~mm}$. Ligeramente rota la parte inferior.

CHRISTUS.- In Dei nomine. Ego Eldara Cresconiz et Luzo Arias a tibi Gontrote Suariz. In Domino Deo eterne salutem, amen. Ideo placuit michi per bona / pacis et volumptas ut faceremus a vobis kartula venditionis sicut et facimus de ereditate propria que abemus de ganantia. / Et iacet ipsa ereditate in villa quos vocitant Meitiriz, subtus monte Aural, prope aula Sancti Michaelis, flubio Deza, arrogio / Mera, et iacet in casare de tiu Sandino; de media, VI ${ }^{\mathrm{a}}$ quinione de Ordonio et de quinione de Menendo Trasmiri, de abolo et de gaenancia (sic), mediatate / integra de illa ereditate de Veremudo Menendiz qui fuit de Pelagio Trasmiriz, mediatate quantum ganavit Arias Veremudiz et sua / mulier in ipso kasare dedit ad Gontrote Suariz cum omnis bona sua prestantia per suis terminis et locis antiquis, per ubi illa / potueritis invenire, pro que accepimus de vos in precio solidos $\mathrm{XXX}^{\mathrm{a}}$ de dinarios, tantum nobis et vobis bene complacuit. Ita ut de odie die / vel tempore de iuri vestro abrasa et in vestro iure vel dominio si tradita atque confirmata; abeatis vos et omnis posteritas vestra. /

Si quis tamen, quod fieri non credo, aliquis omo contra hanc karta ad irrumpendum venerit vel venerimus, propinquis vel extraneis, / quomodo pariat ipsa ereditate dublata vel triplata et quieta; et vos perpetim abitura.

Facta karta vendicionis / in concilio Sancti Michaelis, era $\mathrm{I}^{\mathrm{a}} \mathrm{C}^{\mathrm{a}} \mathrm{LXXV}$, et quotum IIII $^{\circ}$ idus december.

Froi (Froi: tachado) Ego Luzo Arias et Eldora Cresconiz / in hanc karta manus nostras rovoravimus.

Qui presentes fuerunt: Petro ts., Froia presbiter ts. cf., / Ramiro presbiter cf.

Abeco qui notuit.

«CUADERNOS DE ESTUDIOS GALLEGOS», Tomo L, Fascículo 116, Santiago 2003 
1145, febrero, 20.

Pedro Suárez cede a su hermana Guntrodo la heredad de Quintana en la parroquia de Santa María, en Tierra de Dozón, a cambio de otra heredad en Palacios de Monte, en Aguada.

MADRID, $A H N, 1509 / 11$, perg., orig., minúscula carolina, 330 x $125 \mathrm{~mm}$.

CHRISTUS.- In Dei nomine. Ego Petro Suariz a tibi iermana mea domna Gonterodo Suariz. In Domino Deo eterna Salute, amen. Placuit michi atque convenit, nullis quo egentis inperio / nec suadentis articulo, sed propria michi accessit bone pacis volumtas, ut facerem a vobis textum scripture et kartule vendicionis de hereditate mea propria / que habeo de pater meo Suario Petriz. Et iacet ipsa hereditate in territorio Decon, subtus monte Mamona de Cuiarro iusta ecclesia Sancta Maria, secus flumine Decon, in loco predicto / Quintana, meo quinione. Et accepit inde pro illa alia hereditate in Palaciis de Monte, iusta Aquaada, quinio suo de mea iermana domna / Gunterodo Suariz; et sedeat firmiter istum scriptum vel ipsas conkambiacionis. Concedo a vobis ipsa mea hereditate de Quintana a iermana mea per ubi potueritis invenire / per suis terminis antiquis, tam intus quam de foris; et quicquid voluerit facere, inde facia sive a vitta et post obitum suum.

Si quis tamen, quod fieri non credimus, aliquis homo de mea / parte, tam filiis meis aut quam extraneis, illa miserit in calumpnia, componat illa in duplo a tibi Gunteroda Suariz aut qui voce vestra pulsaverit. /

Facta kartula confirmacionis era .I.C.LXXX.III ${ }^{a}$. et quotum X kalendas marcias.

Ego Petro Suariz a tibi iermana mea Gontero (sic) Suariz in hanc kartulam / confirmacionis manu mea rovoro $(+)$.

In presentia vel in tempore comité Fernando, vel sedis lucensis episcopus Quidus. /

Domna Orraga cf.- Vermudo cf.- Arias cf.

Qui presentes fuerunt: Garcia ts., Fernando ts.-Iohanne ts., Pelagio ts.Didaco ts., Petro ts.

Martinus qui notuit (Signum).

«CUADERNOS DE ESTUDIOS GALLEGOS», Tomo L, Fascículo 116, Santiago 2003. 
1151, marzo, 5.

Las hermanas Aragunta y Toda Fernández con Fernando, Pedro y Rodrigo Sancii, hermanos, cambian con su «amita» doña Guntroda, abadesa de San Pedro de Vilanova, diversas heredades en tierra de Abeancos, recibiendo de la abadesa otras propiedades en las tierras de Ventosa y Asma.

MADRID, $A H N, 1509 / 15$, orig., latín, minúscula carolina, $370 \times 160$ mm., bastante deteriorado.

Observaciones: En este doc. doña Guntroda ya es denominada «monasterii Sancti Petri de Villa Nova domine atque abbatisse». Aunque la fundación de este monasterio se establece en 1154, se deduce que antes de la fundación propiamente física del monasterio ya existía una comunidad que demandaba ese edificio.

CHRISTUS.- Omnis comutatio que scripturarum titulo et bonorum hominum facta dinoscitur presenti firmitudinis robur [...] obtinere comprobatur. Quapropter nos Aragunti Fernandiz et Toda Fernandiz sorores, / Hernandus Sancii et Petrus Sancii et Rodericus Sancii fratres, nullo cogente nec suadente, set grato animo ac spontanea voluntate, facimus / cartulam comutationis vobis amite nostre domne Guntrode, monasterii / Sancti Petri de Villa Nova domine atque abbatisse, de hereditate nostra propria quam habemus ex parte avorum et parentum nostrorum in terra de Aviancos; videlicet, quartam partem integram de ecclesia Sancti Felicis de Ripa de Ulia / cum omni iure suo, et in Ventosa medietate integra de ecclesia Sancti Michaelis de Lagenosa similiter cum omni iure suo, que nobis iure hereditario conveniunt; quas ecclesias damus et concedimus vobis iam dicte et / voci vestre per presentis scripture titulum iure hereditario perpetuo possidendas. A modo supradicta hereditas de iure nostro ablata et in vestro iuri et dominio tradita et confirmata, ita quod faciatis de ea quidquid vobis placuerit / in vita et in morte.

Si quis tamen, quod fieri non credimus, tam de nostris quam de extraneis contra hoc nostrum factum ad irrumpendum venire presumpserit qualiscumque sit quod sub calumpnia miserit, in duplo vel triplo /

«CUADERNOS DE ESTUDIOS GALLEGOS», Tomo L, Fascículo 116, Santiago 2003. 
componat; et hoc nostrum factum (nostrum: tachado) nullominus irrumpere queat, set firmum et stabile sit in perpetuum.

Accepimus autem a vobis pro supradicta hereditate in comutatione hereditates alias in Ventosa: integram portionem / vestram quantam vobis convenit in monasterio de Orrea cum omni iure suo, et in terra de Asma integram portionem vestram de monasterio Sancti Migael de Insula similiter cum omni iure suo sicut vobis convenit, precium quod nobis / satis complacuit.

Facta comutationis carta era $\mathrm{M}^{\mathrm{a}}$. $\mathrm{C}^{\mathrm{a}}$. $\mathrm{LXXX}^{\mathrm{a}}$. VIIII ${ }^{\mathrm{a}}$ et quotum $\mathrm{III}^{\circ}$ nonas marcii.

Nos superius [no]m[inati] Aragunti Fernandiz et Toda Fernandiz et Fernandus Sancii et Petrus Sancii et Rodericus Sancii [...] propriis manibus roboramus et cf. $(+)$.

[...] Fernandus[...] [...]nore in Gallecia et in Monterroso cf. / [....Petrus $]$ Bazacus

cf. $[\ldots] \mathrm{cf}$.

Petrus ts., Iohannes ts., Rudericus [ts.]

$L$ ?etius notuit.

1152, febrero, 22.

Arias Luz pacta con Suero Pérez y su hija Guntrodo Suárez sobre unas heredades en San Esteban de Portela, Palacios, San Miguel de Luinosa y en San Fiz de Ribadulla.

MADRID, $A H N, 1508 / 1$, perg., orig., latín, visigótica caligráfica, 176x175 mm., mal conservado.

CHRISTUS.- Era I C L XXXX et quodum VIII kalendas marcias. / Ego Arias Luzi facimus pactum [...] et placitum per scriptum ligabile / firmitatis ad tibi Suario Petri et ad filia vestra Gontrode Suariz / pro illas hereditates que tibi damus de nostras manus ad tenendum. / Hec sunt: villa de [...] et alia de [...] de Sancto Stephani de Portell<a $>$, / alia de Faton, alia de Palaciis, una ecclesia de Sancti Migahel de Lainosa, / et 
alia de Sancti Felizi de Ripe Ulie, ut quando petierimus tibi, ego Suario / vel filia mea Guntrote vel voci nostre [...] tornetis eas / in manus nostras pagatas sine ulla kalumnia cum suas popula/tiones, sicut eas invenistis; et non mitatis vos Arias Luz / cum nullo omine nulla suposita mala per ubi eas Gontrote / de illas hereditates kareat.

Et si ego Arias Luzi mentiosus / fuerit et hunc placitum ex[ierit?] et illas hereditates iam superius / nominatas in kalumnia miserit; que pariat Arias Luz in solidos mille / ad tibi Suario et ad Gontrote ad quicque de vobis illas in kalumnia / miserit vel ad qui voce vestra pulsaverit.

Ego Arias Luz in hoc / placitum legentem audivi et manu mea rovoravi $(+)$.

Qui presentes fuerunt: Petro ts., Pelagio ts., Veremudo ts.

Enila Mgc confirma, Pelaguis Baldemiriz confirma, Oduario Aldiz confirma.

Gondesindus qui notuit $(+)$.

1152, diciembre, 1

Urraca Suárez vende a Guntrodo Suárez la villa de Agrosagro en la parroquia de San Esteban, tierra de Camba, por 10 sueldos.

MADRID, $A H N, 1509 / 17$, perg., orig., latín, visigótica caligráfica, 557 x 95 mm.

In Dei nomine. Ego Oraka Suarizi ad tibi Gumterode Suarizi. Placuit nobis per bona pacis voluntas nostre ut venderemus ad vobis mea ereditate probia que abeo de mea mater Goina Pelaici. Et est ipsa ereditate in tera / Kanba, subtus monte Navego, discurente ribulo Arnego, sub aula domus Sancti Stefani, vila pernominata Arbosagro, quantam me compota (sic) inter meos fratres vel erdibus meis. Et acepi de vos precium $\mathrm{X}$ solidos que a nobis bene / conplacuit; et de precio apu (sic) vos nil remansi.

Si quis tamen, quod fieri non credo, aliquis omo de propinquis meis vel de extraneis, calumniare venerint vel venerimus, que pariam nobis ipsa ereditate duplata vel triplata, vobis perpetim / abitura.

«CUADERNOS DE ESTUDIOS GALLEGOS», Tomo L, Fascículo 116, Santiago 2003. 
Facta kartula vendicionis et escriptura firmitatis era .I. C LXXXX et quod erit kalendas december.

Ego Oraka Suarizi in oc kartu/la manus nostras rovoravimus. Qui presentes fuerunt: Petro ts., Pelagio ts., Oduario ts.

Oduarius qui (Signum) notuit.

1155, diciembre, 13.

María Pérez y sus hijos venden a doña Guntrodo Suárez la villa de Agiaz en la parroquia de San Julián, tierra de Ventosa, por un total de 30 sueldos.

MADRID, $A H N, 1509 / 20$, perg., orig., latín, visigótica caligráfica, 440 x $110 \mathrm{~mm}$.

In Dei nomine. [Ego Maria Petrici], una cum filiis meis, ad vobis domina Gontrode Suarici. In Domino Deo eterna salute, amen. Ideo placuit nobis atque convenit, asto animo integroque consilio, nulis quod egentis imperio nec suadentis / articulo, sed propria nobis accessit voluntas ut faceremus tibi domina Gontrode Suarici vel voci tue; fatio tibi Maria Petrici textum scripture et kartula venditionis de ereditate nostra propria que abemus de suscep/tione abiorum vel parentum nostrorum; et habet iacenti (sic) teritorio Ventossa, sub eminenti sumeo, secus alvei Arneci, sub aula Sancto Iuliano, loco predicto villa Agelaz et Riulo, mediatate de quantum potuerit sacare inter / meos parentes vel eredes. Vendimus vobis domos cum utensilia, genus arborum pomiferum vel infecudium, terras cultas et barbaras, aquas incuribiles vel diferentes, exitus montium, accessum vel regressum, quantum a prestitum / hominis est in ipsas villas, tam intus quam de foris; et est terminata per Pena Lada, et inde per Tiduledu, et inde per rivulo Arneci, et inde figese $\mathrm{u}<\mathrm{n}>\mathrm{de}$ in quod primiter avimus. Vendimus vobis illas villas per ubique illas potueritis invenire, per suis terminis et locis antiquis, pro quod accepimus de vos in pretium una vaka et VI solidos de dinarios et uno modio de pan; id est, in totum pretium $\mathrm{XXX}^{\mathrm{a}}$ solidos, pretium que nobis bene complacuit; et de pretium aput vos nichil non remansit in debitum. / Ita ut, de hodie die et tempore, sit ipsa 
hereditate de iuri nostro abras $<\mathrm{a}>$, vestroque dominio confirmata $\mathrm{ev}<\mathrm{0}>$ pereni et in secula cuncta, amen.

Si quis tamen, quod fieri nemo credimus, aliquis homo de / consanguineis meis vel extraneis, contra hanc scriptura kartulam venditionis atentandum vel infringendum venerit, quisquis ille fuerit, componat vobis vel voci vestre sepedicta hereditate duplata / vel triplata vel quantum vobis fuerit meliorata.

Facta kartula venditionis die feria quarta et quot idus kalendas december, era. . $^{\mathrm{a}} \cdot \mathrm{C}^{\mathrm{a}} \cdot \mathrm{LX}^{\mathrm{La}} \cdot \mathrm{III}{ }^{\mathrm{a}}$.

Ego Maria Petrici, una cum filiis meis, in anc / kartula venditionis quem fieri iussimus, manus nostras $(+++)$.

Qui presentes fuerunt: Petro testes, Pellagio testes, Rodrigu testes.

Yldefonsus notuit, confirmo. (Signum).

1160, mayo, 19

(Santa Ougea)

Don Fernando Odariz y doña Guntroda Suárez litigan por la heredad de Rioseco en la villa de Santiago de Carracedo, tierra de Búbal. Los jueces al efecto determinan que la disputa se resuelva mediante arbitrio de»hombres buenos», los cuales dictan el correspondiente laudo.

MADRID, $A H N, 1510 / 4$, perg., orig., latín, minúscula carolina, 175 x $170 \mathrm{~mm}$.

ORENSE, $A C$, extr., Repertorio, p. 129.- $A H P$, extr., cód. 934, fol. 39.

Orta fuit intentio inter Fernando Odariz et Guntrode Suariz super illa hereditate de Rivulo Sicco. / Et devenerunt inde ad iudicium ante comitem Gunzalvum et ante Arias Petriz de Monte Roso et Fernando / Fernandez de Salnes et Fernan Diez de Tavairolos, qui iudicaverunt quod dedisset domnus Fernandus tres milites / et tres villanos ad iuramentum in Sancto Iacobo de Carrazedo, ubi est ipsa hereditas. Et ibi convenerunt homines optimos / inter illos quod dedisset domna Guntrode una mula preciata in $\mathrm{V}^{\mathrm{e}}$ marcos et uno novo de ipsa hereditate et / XX solidos. Et dedit domna Guntrode toto isto avere domno Fernando pro illa hereditate, et domnus Fernandus / annunciavit illa hereditate ad domna Guntrode. Et iacet ipsa 
hereditas in territorio buvalense, discur/rente rivulo Mineo, sub monte Coto, in villa que vocitant Sancti Iacobi de Carrazedo. Ego Fernando Oariz / tibi domna Guntrode annuncio istam hereditatem per ubi eam potueris invenire per omnibus suis terminis et locis / antiquis et accepi de te precium supranominatum quod mihi bene complacuit. Ita ut de iuri meo sit abrasa et in / iuri tuo confirmata; habeas tu firmiter et omnis posteritas tua.

Si autem aliquis homo ad irrumpendum venerit, / quomodo pariat ipsa hereditate duplata vel triplata, et in calumnia regis $\mathrm{D}$ solidos.

Facta cartula annuncia/tionis et venditionis sub die et quodum quod fuit .XIIII. kalendas iunii, era $\cdot \mathrm{M}^{\mathrm{a}} \cdot \mathrm{C}^{\mathrm{a}}$.LXXXX ${ }^{\mathrm{a}}$.VIII ${ }^{\mathrm{a}}$. /

Ego Fernando Oariz et uxor mea domna Tarasia Moninz tibi domne Guntrode Suariz in han cartulam / manus nostras roboramus.

Qui presentes fuerunt: Garsia Rugel, Petro Fumaz, Fernando Maxilla. / Martino testis.- Iohanne testis.- Petro testis.

Regnante rege Fernando in Leone et in Galecia.- Princeps de Monte Roso comes Gunzalvus.- In lucense ecclesia Iohannes episcopus.- In oriensi Petrus episcopus.

(Signum) Pelagius qui notuit.

18

1169, noviembre, 1.

María Pérez dona a su hermana doña Tuda las heredades que tiene en Deza, Tabeirós, Búbal, Asma y otros lugares.

MADRID, $A H N, 1510 / 9$, perg., orig., latín, minúscula carolina, pero con algunas letras todavía de trazado visigótico, $350 \times 135 \mathrm{~mm}$.

Observaciones: Las letras visigóticas se transcriben en cursiva.

Sub Christi nomine. Ego Maria Petriz et omnis vox mea, ad vobis soror mea. In Domino eternam salutem, amen. Placuit michi per bona pacis et per bona volumtatem / ut faceremus ad vobis kartulam de donationis de hereditatem meam propriam quem habeo de meo patre et de mea matre in loco predicto in Deca, / in Taveirolas, in Buval, in Asma,

«CUADERNOS DE ESTUDIOS GALLEGOS», Tomo L, Fascículo 116, Santiago 2003. 
in Camba, in Montes, in Ripa Ulia, in Durra, in Lemus, in Sarria. Quamtum ego habeo de parte de meo patre vel / matre dedero ad vobis Domna Tuda, et concedimus per ubi eam potueritis invenire, montes, fontes, terras cultas vel incultas, arbores fructuosas vel / infructuosas, molinos, ribulos, casas, ecclesias, leigarios. Ego dedero ad vobis pro amore que habuit vobiscum; habeatis possideatis, vendatis, donetis, faciatis / de ea quicquid voluerit et de criacione imperpetuum./

Et si de mea parte vel de extranea parte venerit vel venerimus, quisquis fuerit, pariamus illam hereditatem duplatam vel triplatam et in quan/tum fuerit melioratam, et insuper solidos quingentus milia.

Sub era .I.CC.VII. et quod kalendas novenbrium.

Ego Maria Petriz in istam kartulam meas manus / roboro.

Qui presentes fuerunt: Petrus $t \mathrm{~s}$., Didacus $t$ s., Pelagius $t \mathrm{~s}$.

Petrus Petriz fecit istam kartulam per outorgamento per illo capitulo de Villa Nova impresentia (sic) de domna Tareiga / [...]iz, in dies de rege Fernando et de archiepiscopus Petrus Gudesteiz.

1191, agosto, 1.

Litigio sobre la mitad de la iglesia de Santa Eulalia de Canba y tres casales entre doña Toda, abadesa del monasterio de San Pedro de Vilanova de Dozón y Fernando Gutiérrez. Por medio de hombres buenos, acuerdan que Fernando pague a la abadesa una renta y cumpla otras condiciones.

MADRID, $A H N, 1511 / 6$, perg., orig., latín, minúscula carolina, 185 x 270 mm., bastante deteriorado.

A..B..C.- Era $\mathrm{M}^{\mathrm{a}}$.CC ${ }^{\mathrm{a}}$. $\mathrm{XX}^{\mathrm{a}}$. VIIII ${ }^{\mathrm{a}}$ et quotum kalendas augusti. Orta fuit intentio / inter abbatissa domna Toda Petri et conventu monasterii de Villa Nova / et Fernando Guterriz super hereditates de Pinol et de Santa Eulalia de Camba. Et inve/nerunt in presentiam bonorum hominum; scilicet, Pelagii Bazacu, Pelagii Luigom, ar/[...] Petro Garsia, Martino Petri de Cadron, Afonso Luz Felge/ira, Petro Muniz Tabarra, Fernandus

«CUADERNOS DE ESTUDIOS GALLEGOS», Tomo L, Fascículo 116, Santiago 2003. 
Diaz de Camba, Iohannes Garsia; et quanta inter eos deter/minaverunt sicut [...]um invenientur. Ego abbatissa domna Tota Petri cum omni nostro conventu / de Sancto Petro de Villanova, vobis Fernando Guterriz, facimus pactum et convenientiam de nostra / hereditate de media ecclesia de Sancta Eulalia de Camba et de tres casales, $\mathrm{II}^{\circ}$ in Ermo/sendi et $\mathrm{I}^{\circ}$ in Blues? cum omnia sua directura ut teneatis eas tali pacto, ut omni anno a kalendas / augusti usque ad Sanctum Michaelem detis nobis .XIII. modios de centeno per illum quartarium de / Iohanne Garsie, nisi forte venerit grando vel pruina qui omnia auforat; et etiam clericus qui illam domum tenuerit, quando abbatissa vel aliqua soror de Sancto Petro ad eius domum ve/ nerit, pro posse serviat. Et ego Frenandus Guterriz similiter vobis amicus et vasallus / et adiuvem vos in omni vestra directura pro posse meo.

Si quis igitur tam ex parte regis / vel aliquis homo ad calumpniandam supradictam hereditatem venerit, ego abbatissa domna Toda / Petri cum omni voce monasterii, et vos Fernandus Guterrit similiter adiuvemus nos in vicem pro posse / nostro de equitaturis et de ab in vice, et quando ad iure nostro vel vestrum venerit / in hoc pactum supradictum, sit confirmata. Si vero evenerit ut abitum vestrum / mitatis aut vel seculo mudaveritis, hereditas nostra sit libera et quieta cum / omnia bona sua, et vos Fernandus Guterriz debetis dare .IIII ${ }^{\text {or }}$. boves boni et .II ${ }^{\text {as }}$. vacas / et .XII. reixeilos et duas porcas; et propter illum ganatum dedistis nobis in pignore il/lum casalem de fonte ubi Dominicus maiat. Et hoc pactum semper sit firmum.

Si quis vero utrque parte hoc pactum frangere temptaverit, in primis sit maledictus, et / pulsanti eius voce pectet $\mathrm{C}^{\mathrm{m}}$ morabitinos et hoc scriptum semper sit firmum. /

Qui presentes fuerunt: Munio ts., Pelagius ts., Petrus ts.

Iohannes qui notuit et confirmat (Signum). 
[S. XII]

Relación de propiedades donadas por Pelayo Martínez y su mujer Doña Guntroda «Deo vota».

MADRID, $A H N, 1511 / 16$, perg., orig., latin, visigótica caligráfica, $95 \times 250 \mathrm{~mm}$.

Hec est noticia de hereditate de ospitale / que donavit ille Pelagio Martinz / et sua mulier dona Guntrode, Deo vota: in Megimenci quanta ei de suas arras; / in Cunarro quanto ganavit cum suo / marido; in Maurigaes aquele casa/re que ganavit cum suo marido / de Petro Afonso; in Perera que ganavit / de Monio Ariz; in Banicili quanto / ganavit cum suo marido; Arvore/sagro (qufi: tachado) de Susano quanto ganavit / cum suo marido; in Arvosagro de Iu/sano quanto exquiserem de Petro Luce; / in Sancti Stefanus casare medio de Arias / Petriz; castro medio de Pelagio Mili/diz; Kavalaria in Arnego quanta ei / de sua matre; in Ventosa in quasa / de Afonso Vermuz quanto ganavit; de Lageosa uno casare / in casar de Munio Sariz.

21

1205, diciembre, 22.

Teresa Arias dona a Urraca Gómez, abadesa de San Pedro Vilanova de Dozón las heredades que tiene en Barrán, Paredes, Santiago de Arnego y Santa María de Carballeda, y en otros lugares.

MADRID, $A H N, 1512 / 5$, perg., orig., minúscula carolina, 275 x $90 \mathrm{~mm}$., bastante deteriorado.

Observaciones: Las letras «e» $\mathrm{y}$ «g» son visigóticas cursivas.

[In] Dei [nomine]. Ego Terasia Arie vobis Urraca Gomez, abatisse Ville Nove et priori Marie Petri cum omni conventu monasterii, facio cartula anuntio/nis de hereditate mea propria in Amor et casar de Figeiru Odoarie

«CUADERNOS DE ESTUDIOS GALLEGOS», Tomo L, Fascículo 116, Santiago 2003. 
in Baran, casar de Badin in Paredes Seragita (su: tachado) super casale et de Santa Maria et de Santo Iacobo de Ar/nego et a Santa Maria de Carvaleda totum meum quinionem mando cum corpore meo ad Sanctum Petrum, do et benedico in perpetuum.

$\mathrm{Si}$ aliquis ex parte mea / turbaverit anc cartulam ad irrumpendum venerit, sit maledictus et pariat regis mille moravetinos.

Facta carta sub era $\mathrm{M}^{\mathrm{a}} \mathrm{CC}^{\mathrm{a}} \mathrm{XXXX}$ 政 et quod XI / kalendas ianuarii.

Qui presentes fuerunt: Petrus, Martinus, Fernandus.

Et Petrus M. qui notuit (Signum).

1229.

María Petri de Garavelus cambia con sus sobrinos medio casal en Vilacova, por otro medio casal en Dozón, villa de Moi, parroquia de Santiago de Saa.

MADRID, $A H N, 1517 / 4$, perg., orig., carta partida por a.b.c., latín, gótica, $110 \mathrm{x}$ $240 \mathrm{~mm}$.

A..B..C.- In Dei nomine. Sub era M $^{\mathrm{a}}$.CC ${ }^{\mathrm{a}}$.LX $\mathrm{X}^{\mathrm{a}}$.VII ${ }^{\mathrm{a}}$. Maria Petri de Gara/velus cambio cum filiis et filiabus fratris mei Arie Petri: do / illis unum medium casalis in Villa Cova quod emi pro denariis / meis, pro alio medio casalis in Decon, sub catena Sancti Iacobi / de Saa, in villa quod dicitur Moe. Ego do eis medium casalis / cum omnibus suis pertinenciis, excepto inde illud quod dedi Ruderico / Menendi in Agro Sex, et similiter illi dant mihi illud casale cum / suis pertinenciis, excepto et si forte quod aliquis pro voce mea ire / voluerint contra hanc cambiam et ego non possum defendere eos, illi / supradicti habeant per medium casale de Iohanne Iohannis et / per medium forum Fernandi Mauri.

Testes autem huius rei sunt isti: Rudericus Petri, Gundisalvus Ruderici, Lupus Velasci / Aria Ruderici, Petrus Ruderici, G. Velasci, Petrus Micalu, / Rudericus Velasci.

Ego Maria Petri cambio supradicta hereditatem / cum Pelagio Arie et cum Maria Arie et cum Uraca Arie et / cum Maria Menendi, tali conditione 
quod, si ipsi venerint ad cambiam, / mee voci pectet .D. solidos; et si mea vox venerit ad cambiam, / similiter faciat eis. Preterea, isti supradicti defendant / me et voce mea cum hac hereditate.

(Al pie, en letra carolina de fines del S. XII) Maria Petri, concambiu que feci in Dezum.

1249 , septiembre.

Pedro Martínez y su mujer doña Eximia venden a la abadesa de San Pedro de Vilanova de Dozón un casal en Munín, por 80 sueldos, recibiendo aquellos dicho casal en usufructo.

MADRID, $A H N, 1525 / 2$, perg., orig., latín, gótica, 210 x 170 mm., bastante deteriorado.

A..B..C.- In Dei nomine. Notum sit presentibus et futuris quod nos S. abatisa et conven/tus de Dezon damus et concedimus, spontanea voluntate, casale quod habemus in Mu/nim? et est in filigregia Sancti Iacobi, vobis Petro Martini dicto Pedrero et uxori / vestre domne Eximie de Campo quod, habeatis illud in vita vestra amborum pro LXXX ${ }^{\text {ta }}$ solidos nominatim / quod nos debemus dare vobis in festo Sancti Martini; et nos debemus amparare supradicto / casale con quarenta morabetinos. Et ipse supradictus Petrus Martini et uxor sua dona Exim/ia pacaverit nos pro primus annus [...] quia dederunt nobis .CCC. et .L. solidos nominatim / et primo anno $[\ldots .$.$] fructus et directuras et ita quod anni VI [...]/si in termino sex annos$ hereditatem acceperunt debent habere per illud casale supradictus / denarios de quibus [...] atque de ille mandaverint, et nos recepimus domna Eximia / et P. Martini pro nostris familiaribus et Petrus Martini et donna Eximia quatum ibi $[\ldots] /[\ldots]$ in pace et in morte et in vita amborum et hereditas maneat[...]/ [...].

Facta carta sub era Ma.CC. LXXX VIIII ${ }^{a}$ et quotum / septembris.

Qui presentes fuerunt: M. clericus, A. monacus clericus, M. monacus, Laurencius / [...]es et iudex [...] Ihoannis clericus./

[...] Iohannis iuratus notarius de Dezon qui notuit. 
1259, marzo, 3.

Ruy Méndez vende a su hermano Juan lo que tiene en Carballo Longo y en Vilanova por cien sueldos.

MADRID, $A H N, 1517 / 6$, perg., orig., gallego, gótica, 110 × 240 mm.

Observaciones: Las palabras y letras interlineadas en el original se transcriben en superíndice.

Era .Ma . CC.LX ${ }^{\mathrm{L}}$.VII. Connozuda cousa seea / a tudolos que sun e an de seer que eu Ruy M/eendez fazo a ti Johan Meendez meu irmao carta de ven/dizon e a tuda tua voz d'aquela erdade de / Carvalo Longo cum a a outra de Villa No/va, quante (sic) o foro de Marina Christiana qual / me

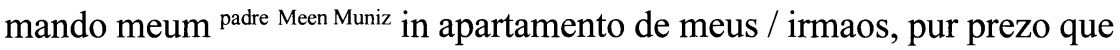
min e a el ben plaz, pur C soldos, e outorgome pur pagado de todo / prezo. Vendo ela asi a vos cun as seydas et cu/n as entradas et cun tudos seus foros asy co/[mo o]s eu a $\mathrm{g}^{\mathrm{h}} \mathrm{oz}$ (sic); da mia parte rasa, in a vosa/[sa c]onfirmada.

E se algen veer da mia par $<$ te $>$ / vel d'estraa contra esta carta, agaz a maldi/zon de Deus et pecti aa parte du rei $\mathrm{C}$ soldos / <et $>$ a carta fique in sua revor, et pecti esa erdade / dublada.

Tres dias andados de marzo, rey de Leon et Castella, Toledo, Murza, Geen, Cor/dova et Sivilla, don Afonso; seu meirino mayor / in Galiza, don Ruy Garcia; rycome en Limia / don Fernan Anes; meirino in Limia, / Ruy Garcia; juiz, / don Stevao Pelaez; bispu in Auriense, don J. Diaz; / dayan, don J. Rico; seu vigariu in Riba de Mi/no, Martin Muniz de Toen.

Qui presentes furon: Petrus Moogo ts., Fernan Pelaez ts., Johan Pedrez. Eu Petrus Martin, notariu et prelado de Gestoso ts. 
1295, enero, 29.

La abadesa de Vilanova de Dozón, doña Teresa Rodríguez, concede en foro a Fernán Díaz y a María Paa, su mujer, el casar de Alemparte, en San Miguel, por pago de dos cuarteros de pan, una regueifa y cuatro gallinas.

MADRID, $A H N, 1537 / 18$, perg., orig., gallego, gótica de albalaes, $160 \times 250 \mathrm{~mm}$.

Observaciones: El signo que precede a las dos $\mathrm{X}$ de la data, por su morfología recuerda a la «X horizontal» visigótica. Aceptando que se trate de una X, la fecha resultante sería 1295; el día del mes no ofrece dudas. Sin embargo, en la suscripción del notario se expresa que el rey es don $F$, pero en 1295 todavía reina Sancho IV (que no muere hasta abril del mismo año). Por otra parte, la abadesa que se menciona no resultaría discordante en tal fecha. Así pues, sólo cabe pensar que el notario, por razones desconocidas, hubiera cruzado la « «\$ de «Sancho» con un trazo horizontal, convirtiendo involuntariamente dicha «s» en una «f».

Finalmente, a falta de otra explicación, puede pensarse que el notario omitió una «I» al final de la data: de esta forma, la fecha se correspondería con el rey Fernando IV, sin contradecir la cronología de la abadesa.

Era de mill CCC XXX et III anos, o quot tres dias / por andar de janeyro.

Cunucuda cosa seya a / quantos esta carta vyren, como nos donna / Tereisa Rodrigues, abbadesa do mosteyro de Villa Nova / de Deçon; et convento dese lugar, damos et outorgamos / a vos, Fernan Diaz, et a vosa muller Maria Paa/, et hun voso filo Johan Vidall, o noso casar / d'Allenparte, que he su cadea de San Miguell de / Goyas, a ter de nos; et que nos dedes dell de / renda cada ano II quarteiros pela tega de / Jagan que leva quatro ceremis dereytas, / esta sega sen $\mathrm{g}<\mathrm{r}>$ ando et sen geada, et huna re/feifa (sic) et IIII galinas

Et contra esto quiser / pasar, aga a malldicon de Deus et peyte a voz / do rey $\mathrm{C}$ moravedis, et a carta vala en sua revor /.

Ts. Domingo Eanes, capelan, et Miguell Lourenzo, Vasquo / Fernandez.

$\mathrm{Eu}$, Miguel Martins, (Signo) notario / jurado en tera de Decon de mao [...] / Lourenço Rodrigues, notario del rey don F. en t[erra de] / Bubal et de Castela, et do Bolo de Senda d[...] / que presente foy, vista (sic) esta carta por mand[ado] / das partes escrivy.

«CUADERNOS DE ESTUDIOS GALLEGOS», Tomo L, Fascículo 116, Santiago 2003. 
Tabla I.- Esquema diplomático

\begin{tabular}{|c|c|c|c|c|c|c|c|c|c|c|c|c|c|c|c|c|c|c|c|c|c|c|c|c|c|c|c|c|}
\hline \multirow[b]{2}{*}{$\mathrm{N}^{\circ}$} & \multirow[b]{2}{*}{ Fecha } & \multirow{2}{*}{ 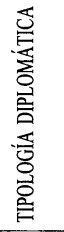 } & \multicolumn{6}{|c|}{ Invocación } & \multirow{2}{*}{ 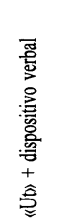 } & \multirow{2}{*}{ 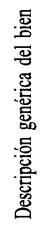 } & \multicolumn{3}{|c|}{ Precio } & \multicolumn{4}{|c|}{$\begin{array}{l}\text { Transmisión } \\
\text { de dominio }\end{array}$} & \multicolumn{2}{|c|}{ Sanciones } & \multicolumn{3}{|c|}{ Data } & \multicolumn{2}{|c|}{ Roboración } & \multicolumn{3}{|c|}{$\begin{array}{c}\text { Testigos- } \\
\text { Confirmantes }\end{array}$} & \multirow[b]{2}{*}{ 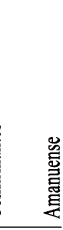 } \\
\hline & & & 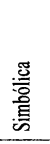 & 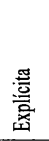 & 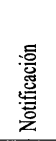 & 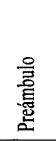 & 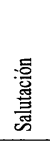 & 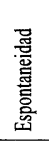 & & & 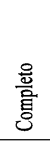 & $\begin{array}{l}\text { 을 } \\
\text { 总 } \\
\text { 惫 } \\
n\end{array}$ & 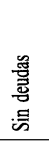 & 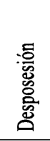 & $\begin{array}{l}\text { 貓 } \\
\text { 至 }\end{array}$ & 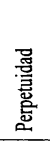 & 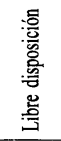 & 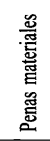 & 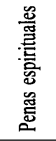 & 峷 & 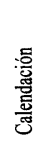 & 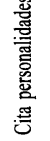 & 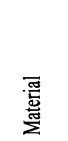 & $\begin{array}{l}\text { 墨 } \\
\text { 䴦 } \\
\text { 言 }\end{array}$ & 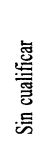 & 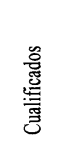 & 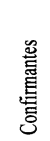 & \\
\hline 1 & 1015 -II-28 & $\mathrm{CV}$ & & $\mathrm{X}$ & & & $\mathrm{X}$ & $\mathrm{X}$ & $\mathrm{X}$ & $\mathrm{X}$ & $\mathrm{X}$ & $\mathrm{X}$ & $\mathrm{X}$ & $\mathrm{X}$ & $\mathrm{X}$ & $\mathrm{X}$ & $x$ & & & $\mathrm{X}$ & $\mathrm{X}$ & & $\mathrm{X}$ & $\mathrm{X}$ & $\mathrm{X}$ & & & $\mathrm{X}$ \\
\hline 2 & 1082-XII-18 & $\mathrm{D}$ & $\mathrm{X}$ & $\mathrm{X}$ & & & $\mathrm{X}$ & $\mathrm{X}$ & $\mathrm{X}$ & $\mathrm{X}$ & & & & & $\mathrm{x}$ & & $X$ & $\mathrm{X}$ & & $\mathrm{x}$ & $\mathrm{X}$ & & & $\mathrm{X}$ & $\mathrm{x}$ & & & $\mathrm{X}$ \\
\hline 3 & 1084-IV-27 & $\mathrm{D}$ & $\mathrm{X}$ & $\mathrm{X}$ & & $\mathrm{X}$ & & & $\mathrm{X}$ & $\mathrm{X}$ & & & $\mathrm{X}$ & $\mathrm{x}$ & $\mathrm{x}$ & $\mathrm{X}$ & $\mathrm{X}$ & $\mathrm{X}$ & & $\mathrm{x}$ & $\mathrm{X}$ & & & $\mathrm{X}$ & $\mathrm{x}$ & & & \\
\hline 4 & 1085-II-29 & $\mathrm{CV}$ & & $\mathrm{X}$ & & & $\mathrm{X}$ & & $\mathrm{X}$ & $\mathrm{X}$ & $\mathrm{X}$ & $\mathrm{X}$ & & $\mathrm{X}$ & $\mathrm{x}$ & & & $\mathrm{X}$ & & $\mathrm{X}$ & $\mathrm{X}$ & & & $\mathrm{X}$ & $\mathrm{X}$ & & & $\mathrm{X}$ \\
\hline 5 & 1097-VIII-18 & D & & $\mathrm{X}$ & & & $\mathrm{X}$ & $\mathrm{X}$ & $\mathrm{X}$ & $X$ & & & & & & & & & & $\mathrm{X}$ & $\mathrm{X}$ & & & $\mathrm{X}$ & $\mathrm{X}$ & & & $\mathrm{X}$ \\
\hline 6 & 1097-VIII-18 & $\mathrm{CV}$ & & $\mathrm{X}$ & & & $\mathrm{x}$ & $\mathrm{X}$ & $\mathrm{X}$ & $\mathrm{X}$ & $\mathrm{X}$ & $\mathrm{X}$ & & & & $\mathrm{X}$ & & $\mathrm{X}$ & & $\mathrm{X}$ & $\mathrm{X}$ & & & $\mathrm{X}$ & $\mathrm{X}$ & & & $\mathrm{X}$ \\
\hline 7 & 1106-XI-05 & $\mathrm{CV}$ & $\mathrm{X}$ & $\mathrm{X}$ & & & $\mathrm{X}$ & $\mathrm{X}$ & $\mathrm{X}$ & $\mathrm{X}$ & $\mathrm{x}$ & & & $\mathrm{x}$ & $\mathrm{X}$ & & & $\mathrm{X}$ & & $\mathrm{X}$ & $\mathrm{X}$ & & & $\mathrm{X}$ & $\mathrm{X}$ & & & $\mathrm{X}$ \\
\hline 8 & 1106-XII-28 & $\mathrm{CV}$ & $\mathrm{X}$ & $\mathrm{X}$ & & & $\mathrm{X}$ & $\mathrm{X}$ & $\mathrm{X}$ & $X$ & $\mathrm{X}$ & $\mathrm{X}$ & $\mathrm{X}$ & $\mathrm{x}$ & $\mathrm{X}$ & $\mathrm{X}$ & & $\mathrm{x}$ & & $\mathrm{X}$ & $\mathrm{X}$ & & & $\mathrm{X}$ & $\mathrm{X}$ & & & \\
\hline 9 & 1116-XI-27 & $\mathrm{CV}$ & $\mathrm{X}$ & $\mathrm{X}$ & & & $\mathrm{X}$ & $\mathrm{X}$ & $\mathrm{X}$ & $\mathrm{X}$ & $\mathrm{X}$ & $\mathrm{X}$ & $\mathrm{X}$ & $\mathrm{X}$ & $\mathrm{X}$ & $\mathrm{X}$ & & $\mathrm{x}$ & & $\mathrm{X}$ & $\mathrm{X}$ & $\mathrm{X}$ & & $\mathrm{X}$ & $\mathrm{x}$ & & & $\mathrm{X}$ \\
\hline 10 & $1133-X I-29$ & $\mathrm{CV}$ & & $\mathrm{X}$ & & & $\mathrm{X}$ & $\mathrm{X}$ & $\mathrm{X}$ & $\mathrm{X}$ & $\mathrm{x}$ & $\mathrm{X}$ & $\mathrm{X}$ & $\mathrm{X}$ & $\mathrm{x}$ & $\mathrm{X}$ & & $\mathrm{X}$ & & $\mathrm{x}$ & $\mathrm{X}$ & & & $\mathrm{X}$ & $\mathrm{x}$ & & $\mathrm{X}$ & $\mathrm{X}$ \\
\hline 11 & 1137-XII-10 & $\mathrm{CV}$ & $\mathrm{X}$ & $\mathrm{X}$ & & & $\mathrm{X}$ & $\mathrm{X}$ & $\mathrm{X}$ & $\mathrm{X}$ & $\mathrm{X}$ & $\mathrm{X}$ & & $\mathrm{x}$ & $\mathrm{X}$ & $\mathrm{X}$ & & $\mathrm{X}$ & & $\mathrm{X}$ & $\mathrm{X}$ & & & $\mathrm{X}$ & $\mathrm{X}$ & & $\mathrm{X}$ & $\mathrm{X}$ \\
\hline 12 & 1145-II-20 & $\mathrm{P}$ & $X$ & $\mathrm{X}$ & & & $\mathrm{X}$ & $\mathrm{X}$ & $\mathrm{X}$ & & & & & & $\mathrm{x}$ & $\mathrm{X}$ & $\mathrm{X}$ & $\mathrm{X}$ & & $\mathrm{X}$ & $\mathrm{X}$ & $\mathrm{x}$ & & $\mathrm{X}$ & $\mathrm{X}$ & & $\mathrm{X}$ & $\mathrm{X}$ \\
\hline 13 & 1151-III-05 & $\mathbf{P}$ & $\mathrm{X}$ & & & $\mathrm{X}$ & & $\mathrm{X}$ & $\mathrm{X}^{*}$ & & & & & $\mathrm{X}$ & $\mathrm{x}$ & $\mathrm{X}$ & $\mathrm{X}$ & $\mathrm{X}$ & & $\mathrm{X}$ & $\mathrm{X}$ & & & $\mathrm{X}$ & $\mathrm{x}$ & & $\mathrm{X}$ & $\mathrm{X}$ \\
\hline 14 & 1152-II-22 & A & & & & & & & $\mathrm{X}^{*}$ & & & & & & $\mathrm{X}$ & & & $\mathrm{X}$ & & $\mathrm{X}$ & $\mathrm{X}$ & & & $\mathrm{X}$ & $\mathrm{x}$ & & $\mathrm{X}$ & $\mathrm{X}$ \\
\hline 15 & 1152-XII-01 & $\mathrm{CV}$ & & $\mathrm{X}$ & & & $\mathrm{X}$ & $\mathrm{X}$ & $\mathrm{X}$ & & $\mathrm{x}$ & $\mathrm{X}$ & $\mathrm{X}$ & & & & & $\mathrm{x}$ & & $\mathrm{X}$ & $\mathrm{X}$ & & & $\mathrm{X}$ & $\mathrm{X}$ & & & $\mathrm{X}$ \\
\hline 16 & 1155-XII-13 & $\mathrm{CV}$ & $X$ & & & & $\mathrm{X}$ & $\mathrm{X}$ & $\mathrm{X}$ & $\mathrm{X}$ & $\mathrm{X}$ & $\mathrm{X}$ & $\mathrm{X}$ & $\mathrm{X}$ & $\mathrm{X}$ & $\mathrm{X}$ & & $\mathrm{X}$ & & $\mathrm{X}$ & $\mathrm{X}$ & & & $\mathrm{X}$ & $\mathrm{X}$ & & & $\mathrm{X}$ \\
\hline 17 & $1160-\mathrm{V}-19$ & A & & & & & & & $\mathrm{X}^{*}$ & & $\mathrm{x}$ & $\mathrm{X}$ & & $\mathrm{x}$ & $\mathrm{x}$ & $\mathrm{X}$ & & $\mathrm{X}$ & & $\mathrm{X}$ & $\mathrm{X}$ & $\mathrm{X}$ & & $\mathrm{X}$ & & $\mathrm{X}$ & & $\mathrm{X}$ \\
\hline 18 & 1169-XI-01 & D & & $\mathrm{X}$ & & & $\mathrm{X}$ & & $\mathrm{X}$ & $\mathrm{X}$ & & & & & & $\mathrm{X}$ & $\mathrm{X}$ & $\mathrm{X}$ & & $\mathrm{X}$ & $\mathrm{X}$ & $\mathrm{X}$ & & $\mathrm{X}$ & $\mathrm{x}$ & & & \\
\hline 19 & 1191-VIII-01 & A & & & & & & & $\mathrm{X}$ & & & & & & & & & $\mathrm{X}$ & $\mathrm{X}$ & & & & & & $\mathrm{X}$ & & & $\mathrm{X}$ \\
\hline 20 & [Siglo XII] & $\mathrm{N}$ & & & $\mathrm{X}$ & & & & & & & & & & & & & & & & & & & & & & & \\
\hline 21 & $1205-\mathrm{XII}-22$ & D & & $\mathrm{X}$ & & & & & $\mathrm{X}^{*}$ & & & & & & $\mathrm{X}$ & $\mathrm{X}$ & & $\mathrm{X}$ & $\mathrm{X}$ & $\mathrm{X}$ & $\mathrm{X}$ & & & & $\mathrm{X}$ & & & $\mathrm{X}$ \\
\hline 22 & 1129 & $\mathbf{P}$ & & $\mathrm{X}$ & & & & & $\mathrm{X}^{*}$ & & & & & & & & & & & & & & & & & & & \\
\hline 23 & 1249-IX & $\mathrm{CV}$ & & & & & & $\mathrm{X}$ & & & $\mathrm{X}$ & & & & & & & & & $\mathrm{X}$ & $\mathrm{X}$ & & & & & $\mathrm{X}$ & & $\mathrm{X}$ \\
\hline 24 & 1259 & $\mathrm{CV}$ & & & $\mathrm{X}$ & & & & $\mathrm{X}^{*}$ & $\mathrm{X}$ & $\mathrm{x}$ & $\mathrm{X}$ & $\mathrm{X}$ & $\mathrm{x}$ & $\mathrm{X}$ & & & $\mathrm{X}$ & $\mathrm{X}$ & $\mathrm{X}$ & $d^{a}$ & $\mathrm{x}$ & & & & $\mathrm{X}$ & & $\mathrm{X}$ \\
\hline 25 & 1295-I-29 & $\mathrm{F}$ & & & & & & & $\mathrm{X}^{*}$ & & $\mathrm{X}$ & & & & & & & & & $\mathrm{X}$ & $\mathrm{d}^{\mathrm{a}}$ & & & & & $\mathrm{X}$ & & $\mathrm{X}$ \\
\hline
\end{tabular}


Tabla II. Esquemas paleográficos: Escritura Visigótica

\begin{tabular}{|c|c|c|c|c|c|c|c|c|c|}
\hline $\mathrm{N}^{\circ}$ & Fecha & 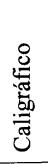 & 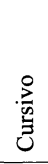 & Mixto & $\begin{array}{c}\text { Características } \\
\text { paleográficas }\end{array}$ & $\begin{array}{l}\text { Calidad } \\
\text { de } \\
\text { escritura }\end{array}$ & 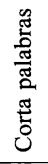 & 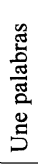 & $\begin{array}{l}\text { Influencias } \\
\text { carolinas }\end{array}$ \\
\hline 2 & 1082-XII-18 & $\mathrm{X}$ & & - & $\begin{array}{l}\text { Contornos } \\
\text { gruesos. }\end{array}$ & $\begin{array}{c}\text { Tosca } \\
\text { y pesada. }\end{array}$ & $\mathrm{X}$ & $\mathrm{X}$ & \\
\hline 3 & 1084-IV-27 & $\mathrm{X}$ & & & $\begin{array}{c}\text { Astiles } \\
\text { prolongados y } \\
\text { finos. Trazado } \\
\text { uniforme. }\end{array}$ & Media & $\mathrm{X}$ & $X$ & \\
\hline 4 & $1085-$ II- 29 & & $\mathrm{X}$ & & $\begin{array}{l}\text { Trazado rápido. } \\
\text { Módulo grande. }\end{array}$ & Media & $\mathrm{X}$ & & \\
\hline 5 & 1097-VIII-18 & & & $\begin{array}{l}\text { Predominio } \\
\text { caligráfico. } \\
\text { Cursividad en } \\
\text { «a», «e», } \\
\text { «g»y «t» }\end{array}$ & $\begin{array}{l}\text { Módulo pequeño. } \\
\text { Astiles elevados. } \\
\text { Contornos } \\
\text { gruesos. }\end{array}$ & Media & & & \\
\hline 6 & 1097-VIII-18 & & & $\begin{array}{l}\text { Predominio } \\
\text { caligráfico. } \\
\text { Cursividad } \\
\text { en «a», «e», } \\
\text { «g»y «t» }\end{array}$ & $\begin{array}{l}\text { Módulo pequeño. } \\
\text { Astiles elevados. } \\
\text { Contornos } \\
\text { gruesos. }\end{array}$ & Media & & & \\
\hline 7 & $1106-X I-05$ & & $\mathrm{X}$ & & $\begin{array}{l}\text { Astiles y caídos } \\
\text { muy prolongados. } \\
\text { Módulo pequeño. } \\
\text { Trazado fino. }\end{array}$ & Media & & $\mathrm{X}$ & \\
\hline 8 & 1106-XII-28 & & $X$ & & $\begin{array}{l}\text { Aspecto redondeado. } \\
\text { Alzados y caídos } \\
\text { prolongados. } \\
\text { Contornos gruesos }\end{array}$ & Buena & & & \\
\hline 9 & 1116-XI-27 & & $\mathrm{X}$ & & $\begin{array}{l}\text { Módulo pequeño. } \\
\text { Alzados prolongados. }\end{array}$ & $\begin{array}{l}\text { Aspecto } \\
\text { claro. }\end{array}$ & & & \\
\hline 11 & 1137-XII-10 & $\mathrm{X}$ & & & $\begin{array}{l}\text { Módulo grande. } \\
\text { Trazos gruesos. }\end{array}$ & Media & & & $\begin{array}{l}\left\langle q^{i} » .\langle e t »\right. \\
\text { tironiano. }\end{array}$ \\
\hline 14 & $1152-$ II- 22 & $\mathrm{X}$ & & & $\begin{array}{l}\text { Astiles prolongados. } \\
\text { Módulo pequeño. } \\
\text { Aspecto redondeado. }\end{array}$ & Media & & & \\
\hline 15 & 1152-XII-01 & $\mathrm{X}$ & & & $\begin{array}{l}\text { Trazado grueso. } \\
\text { Módulo grande. }\end{array}$ & Buena & & $\mathrm{X}$ & $\begin{array}{c}\left\langle q^{i} » y\left\langle{ }^{i} q^{i} s » .\right.\right. \\
\text { «et» tironiano. }\end{array}$ \\
\hline 16 & $1155-X I I-13$ & $\mathrm{X}$ & & & $\begin{array}{l}\text { Trazado grueso. } \\
\text { Alzados y caídos } \\
\text { prolongados. Letras } \\
\text { apretadas lateralmente. } \\
\text { Muy caligráfica. } \\
\text { Aspecto claro. }\end{array}$ & & & & $\begin{array}{c}\text { «qis», «"p } », \\
\mathrm{~m}^{9} .\langle e t » \\
\text { tironiano. }\end{array}$ \\
\hline
\end{tabular}

«CUADERNOS DE ESTUDIOS GALLEGOS», Tomo L, Fascículo 116, Santiago 2003. 
Tabla III. Esquemas paleográficos: Escritura Carolina

\begin{tabular}{|c|c|c|c|c|}
\hline $\mathbf{N}^{\circ}$ & Fecha & $\begin{array}{l}\text { Características } \\
\text { Paleográficas }\end{array}$ & $\begin{array}{l}\text { Calidad de } \\
\text { escritura }\end{array}$ & $\begin{array}{l}\text { Pervivencias } \\
\text { Visigóticas }\end{array}$ \\
\hline 1 & 1015-II-28 & $\begin{array}{l}\text { Aspecto redondeado. } \\
\text { Gruesos y perfiles } \\
\text { equilibrados. } \\
\text { Astiles y caídos cortos. }\end{array}$ & $\begin{array}{l}\text { Buena y clara. } \\
\text { Propia de códice. }\end{array}$ & , \\
\hline 10 & 1133-XI-29 & $\begin{array}{l}\text { Aspecto redondeado. } \\
\text { Gruesos y perfiles } \\
\text { equilibrados. } \\
\text { Astiles y caídos cortos. }\end{array}$ & $\begin{array}{l}\text { Buena y clara. } \\
\text { Propia de códice. }\end{array}$ & \\
\hline 12 & $1145-I I-20$ & $\begin{array}{l}\text { Tendencia angulosa. } \\
\text { Ligera compresión lateral. }\end{array}$ & $\begin{array}{l}\text { Buena. Influencia } \\
\text { cancillería Alfonso VII. }\end{array}$ & Varios «et». \\
\hline 13 & 1151-III-05 & $\begin{array}{l}\text { Aspecto redondeado. } \\
\text { Pocos contrastes } \\
\text { en gruesos y perfiles. } \\
\text { Astiles prolongados. }\end{array}$ & Buena. & \\
\hline 17 & $1160-V-19$ & $\begin{array}{l}\text { Aspecto redondeado. } \\
\text { Gruesos y perfiles } \\
\text { equilibrados. } \\
\text { Astiles y caídos cortos. }\end{array}$ & $\begin{array}{l}\text { Buena y clara. } \\
\text { Propia de códice. }\end{array}$ & \\
\hline 18 & 1169-XI-01 & $\begin{array}{l}\text { Tendencia angulosa. } \\
\text { Ligera compresión lateral. }\end{array}$ & $\begin{array}{l}\text { Buena. Influencia } \\
\text { cancillería Alfonso VII. }\end{array}$ & $\begin{array}{l}\text { Las explicitadas } \\
\text { en la transcripción. }\end{array}$ \\
\hline 19 & 1191-VIII-01 & $\begin{array}{l}\text { Aspecto redondeado. } \\
\text { Gruesos y perfiles } \\
\text { equilibrados. } \\
\text { Astiles y caídos cortos. }\end{array}$ & Buena y clara. & \\
\hline 20 & [Siglo XII] & $\begin{array}{l}\text { Aspecto redondeado. } \\
\text { Astiles y caídos cortos. }\end{array}$ & Escritura rústica y pesada. & \\
\hline 21 & $1205-X I I-22$ & $\begin{array}{l}\text { Aspecto redondeado. } \\
\text { Astiles y caídos cortos. } \\
\text { Módulo grande. }\end{array}$ & Escritura rústica y pesada. & \\
\hline 22 & 1129 & $\begin{array}{l}\text { Aspecto anguloso. } \\
\text { Fuertes contrastes. } \\
\text { Alzados y caídos } \\
\text { incurvados. }\end{array}$ & Escritura cursivizante. & \\
\hline
\end{tabular}

«CUADERNOS DE ESTUDIOS GALLEGOS», Tomo L, Fascículo 116, Santiago 2003. 


\section{MUESTRAS PALEOGRÁFICAS*}

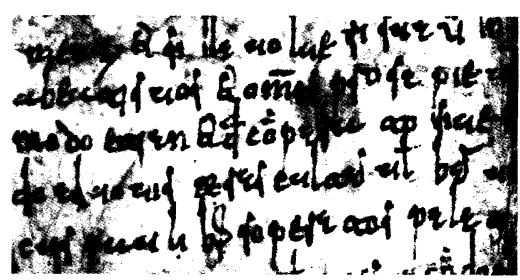

Doc. 4. 1085, marzo, 29

Visigótica cursiva.
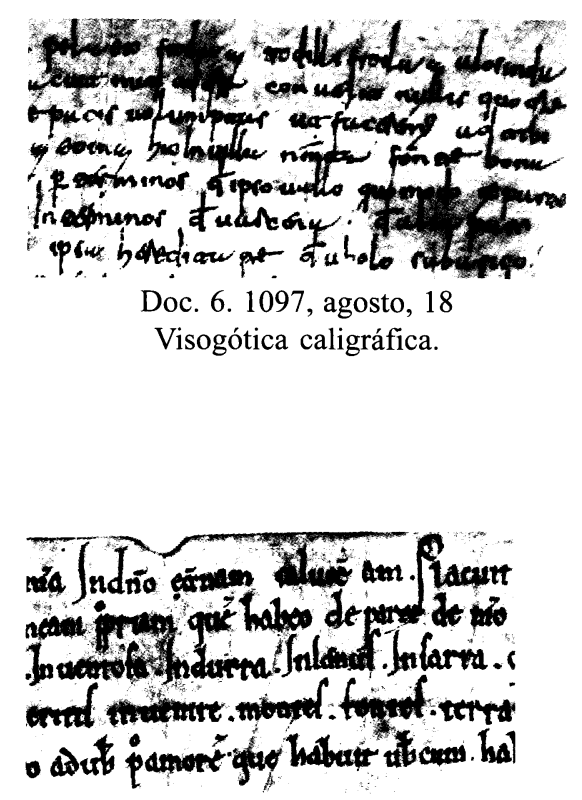

Doc. 18. 1169 , noviembre, 1 Minúscula carolina.
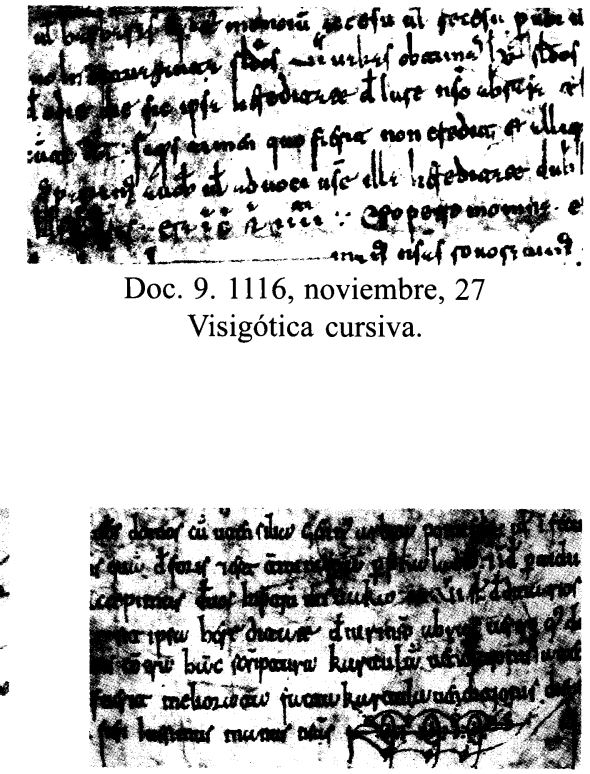

Doc. 16. 1155 , diciembre, 13 Visigótica caligráfica.

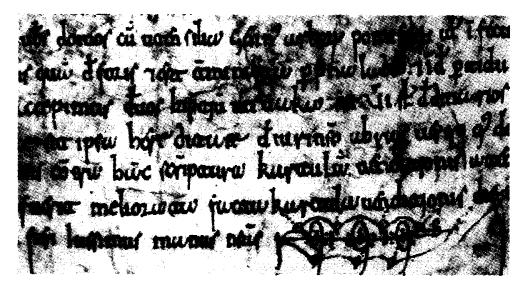

Doc. 10. 1133, noviembre, 29

Minúscula carolina-diplomática.

* Reproducciones digitales: Isam Darwiche Lodeiro (IEGPS-CSIC-XdG).

«CUADERNOS DE ESTUDIOS GALLEGOS», Tomo L, Fascículo 116, Santiago 2003. 


\section{ADVERTENCIA AL ÍNDICE ONOMÁSTICO}

Se encuentran referenciadas aquellas personas que son susceptibles de interés, ya sea por su cargo, estado, profesión o filiación: ésta última se ofrece siempre que el documento la indique.

El número o números que siguen a cada nombre indican el documento o documentos en el que se encuentra.

\section{ÍNDICE ONOMÁSTICO}

Abeco, qui notuit, 11

Adefonsus, abas Sancti Laurenti, 4.

Adefonsus, rey de León, de Castilla y de Galicia, hijo de la reina Orraka, Alfonso VII, 9.

Adosinda Martinz, mujer de Logildo Luz, 7.

Adosinda Pelaiz, madre de Petro Osoriz, 2.

Adosinda, dona, hermana de Pelagio Velasqui/Velasquiz, 4.

Afonso Luz Felgeira, hombre bueno, 19.

Afonso Vermuz, 20.

Afonso, don, rey de León, de Castilla, Toledo, Murcia, Jaén, Córdoba y Sevilla, Alfonso X, 24.

Alosinda Froilaz, hija de Froilaz Gomez, nieto de Sabarico, hermano de Onoricus, Petro, Pelagio, Trodilli y Marina Froilaz, 6.

Alosinda Susmasci, 5.

Aragunti Fernandiz, hermana de Toda Fernandiz, 13.

Aragunti, madre de Sonegildo, 2.

Argilo Quisariquiz, 2.

Aria Ruderici, 22.

Arias Diaz, hijo de Petrus Adefonso y Odrozia Crecosniz, 10.

Arias Eriz, 9.

Arias Luz, 14.- v. Arias Luzi.

Arias Luzi, 14.

Arias Petriz de Monte Roso, 17.
Arias Petriz, 20.

Arias Veremudiz, 11.

Arie Petri, hermano de Maria Petri, padre de Pelagio, Maria y Uraca Arie, 22.

Diagus, abba en San Antonio, 9.

Diagus, obispo de Santiago, 9.

Didacus Iohannis, marido de Sancia Muniz, 1.

Domingo Eanes, capellán, 25.

Eilo Zanitiz, abuela de Gudesteo y Petro Veasquiz, 8.

Eiloni Moniz, 7.

Eldara Cresconiz, 11.

Eldonca Guncalviz, hermana de Munio Guncalviz, 9.

Eldora Cresconiz, 11.- v. Eldara Cresconiz. Elvira Moninz, 9.- v. Elvira Muninz.

Elvira Muninz, hermana de Petro Muninz/ Moninz, nieta de Munio_Guncalviz, mujer de Pelagio Sesnandiz, 9.

Enila Mgc, 14.

Eximia de Campo, doña, mujer de Petro Martini, dicto Pedrero, 23.

F., rey don, 25 (v. las observaciones de este doc.).

Fernan Anes, don, ricohombre en Limia, 24.

Fernan Diaz, marido de Maria Paa, padre de Johan Vidall, 25. 
Fernan Diez de Tavairolos, 17.

Fernan Pelaez, 24.

Fernandi Mauri, 22.

Fernando Fernandez de Salnes, 17.

Fernando Guterriz/Guterrit, 19.

Fernando Maxilla, 17.

Fernando Oariz, 17.- v. Fernando Odariz.

Fernando Odariz, domno, marido de Tarasia Moninz, 17.

Fernando Vimaraz, hijo de Vimara Gunzalviz, 3.

Fernando, comite, 12.

Fernando, rey de León y Galicia, Fernando II, $17,18$.

Fernandus Diaz de Camba, hombre bueno, 19.

Fernandus Guterrit, 19.- v. Fernando Guterriz/Guterrit.

Fernandus Sancii, 13.- v. Hernandus Sancii.

Fernandus, abas, 4.

Frenandus Guterriz, 19.- v. Fernando Guterriz/Guterrit.

Froia Arias, marido de Godina/Gotina Arias, 10.

Froia, presbiter, 11.

Froilaz Gomez, padre de Onoricus, Petro, Pelagio, Trodilli, Alosinda y Marina Froilaz, 6.

G. Velasci, 22.

Garsia Rugel, 17.

Godina Arias, mujer de Froia Arias, 10.

Goina Pelaici, madre de Oraka Suarizi, 15.

Gondesindus, qui notuit, 14.

Gontero Suariz, 12.- v. Gonterodo Suariz.

Gonterodo Suariz, hermana de Petro Suariz, 12.

Gontrode Suarici, domina, 16.

Gontrode Suariz, hija de Suario Petri, 14.

Gontrote Suariz, 11.

Gotina Arias, 10.- v. Godina Arias.

Gotina, Deo vota, 10.

Gudesteo Veasquiz, hijo de Veasco, nieto de Eilo Zanitiz, 8.

Gumterode Suarizi, 15.
Gundisalvus Ruderici, 22.

Gunteroda Suariz, 12.- v. Gonterodo Suariz.

Guntino, padre de Sonegildo, 2.

Guntroda Suárez, doña, Deo vota, 20; mujer de Pelagio Martinz, 20; hija de Suario Petri, 14; hermana de Petro Suariz, 12.

Guntrode Suariz, domna, 17.

Guntrode, domne, 13.

Guntrode, dona, Deo vota, mujer de Pelagio Martinz, 20.

Gunzalviz, padre de Todda, 3.

Gunzalvus, comes, princeps de Monte Roso, 17.

Hernandus Sancii, hermano de Petrus y Rodericus Sancii, 13.

Ihoannes, presbiter, 10.

Ihoannis, clericus, 23.

Iohanne Garsie, 19.- v. Iohannes Garsia.

Iohanne Iohannis, 22.

Iohanne Odarici, marido de Onega Vermuiz, 1.

Iohannes Garsia, hombre bueno, 19.

Iohannes Guterri, notui, 1.

Iohannes, obispo de Lugo, 17.

Iohannes, qui notuit et confirmat, 19.

Iohannis, notario jurado de Dozón, 23.

J. Diaz, don, obispo de Orense, 24.

J. Rico, don, deán, 24.

Jhoan Pedrez, 24.

Johan Meendez, hermano de Ruy Meendez, 24.

Johan Vidall, hijo de Fernan Diaz y de Maria Paa, 25.

Ledegundia, mujer de Sonegildo, 2.

Letius, notuit, 13.

Logildo Luz, marido de Adosinda Martinz, 7.

Lourenço Rodrigues, 25.

Lupus Velasci, 22.

Luzo Arias, 11.

«CUADERNOS DE ESTUDIOS GALLEGOS», Tomo L, Fascículo 116, Santiago 2003. 
Maria Arie, hermana de Pelagio y Uraca Arie, hija de Arie Petri, 22.

Maria Menendi, 22.

Maria Paa, mujer de Fernan Diaz, madre de Johan Vidall, 25.

Maria Petri de Garavelus, hermana de Arie Petri, 22.

Maria Petrici, 16.

Maria Petriz, hermana de domna Tuda, 18. Marie Petri, priora del monasterio de San Pedro Vilanova de Dozón, 21.

Marina Arias, 9.

Marina Arias, mujer de Petrus Gudesteiz, 8.

Marina Christiana, 24.

Marina Froilaz, hija de Froilaz Gomez, nieto de Sabarico, hermano de Onoricus, Petro, Pelagio, Trodilli y Alosinda Froilaz, 6.

Marina Petriz, madre de Sancia Muniz, 1. Martin Muniz de Toen, vicario en Riba de Miño, 24.

Martino Petri de Cadron, hombre bueno, 19.

Martino Velasquiz, hermano de Pelagio Velasquiz/Velasqui, marido de Odrocia Rodoriquiz, 4.

Martinus, qui notuit, 12.

Meen Muniz, padre de Ruy Meendez, 24.

Menendo Trasmiri, 11.

Miguel Martins, notario jurado en tierra de Dozón, notario del rey en tierra de Búbal, de Castilla y del Bolo de Senda, 25 .

Miguell Lourenzo, 25.

Monio Ariz, 20.

Munio Guncalviz, hermano de Eldonca Guncalviz, abuelo de Petro y Elvira Muninz/Moninz, 9.

Munio Odariz, 9.

Munio Sariz, 20.

Munius, comite en Monterroso, 9.

Odrocia Rodoriquiz, mujer de Martino Velasquiz, 4.

Odrozia Cresconiz, mujer de Petrus Adefonso, madre de Petro Diaz y Arias Diaz, 10.
Oduario Aldiz, 14.

Oduarius, qui notuit, 15.

Onega Vermuiz, mujer de Iohanne Odarici, 1.

Onoricus Froilaz, hijo de Froilaz Gomez, nieto de Sabarico, hermano de Petro, Pelagio, Trodilli, Alosinda y Marina Froilaz, 6.

Oraka Suarizi, hija de Goina Pelaici, 15.

Ordonio, 11.

Orraga, domna, 12.

Orraka, regina, madre del rey Adefonsus, 9.

Osorio Muniz, padre de Petro Osoriz, 2.

Ovecus, notuit et confirmat, 9.

Ovequiz, padre del comes Rodrigu, 3 .

Pelagii Bazacu, hombre bueno, 19.

Pelagii Luigom, hombre bueno, 19.

Pelagio Arie, hermano de Maria y Uraca Arie, hijo de Arie Petri, 22.

Pelagio Froilaz, hijo de Froilaz Gomez, nieto de Sabarico, hermano de Onoricus, Petro, Trodilli, Alosinda y Marina Froilaz, 6.

Pelagio Martiniz, 5, 6.

Pelagio Martinz, marido de dona Guntrode, Deo vota, 20.

Pelagio Melidiz, 20.

Pelagio Sesnandiz, marido de Elvira Muninz/Moninz, 9.

Pelagio Trasmiriz, 11.

Pelagio Velasqui.- v. Pelagio Velasquiz, 4.

Pelagio Velasquiz, hermano de Martino Velasquiz y de dona Adosinda, hijo de Velaszo y Elloni, 4.

Pelagio, presbiter, 10.

Pelagio, qui notuit, 10.

Pelagius Baldemiriz, 13.

Pellagio Oduriz, 7.

Petro Afonso, 20.

Petro Diaz, hijo de Petrus Adefonso y Odrozia Cresconiz, 10.

Petro Froilaz, hijo de Froilaz Gomez, nieto de Sabarico, hermano de Onoricus, Pelagio, Trodilli, Alosinda y Marina Froilaz, 6. 
Petro Fumaz, 17.

Petro Garsia, hombre bueno, 19.

Petro Goestez, 9.

Petro Luce, 20.

Petro Martini, dicto Pedrero, marido de domne Eximie de Campo, 23.

Petro Moninz, 9.- v. Petro Muninz.

Petro Muninz, hermano de Elvira Muninz/

Moninz, nieto de Munio Guncalviz , 9.

Petro Muniz Tabarra, hombre bueno, 19.

Petro Osoriz, ahijado de Sonegildo, hijo de Osorio Muniz y de Adosinda Pelaiz, 2.

Petro Pelaiz, 9.

Petro Suariz, hermano de domna Gonterodo/Gunteroda/Gontero Suariz, hijo de Suario Petriz, 12.

Petro Veasquiz, hijo de Veasco, nieto de Eilo Zanitiz, 8.

Petrus Adefonso, marido de Odrozia Cresconiz, padre de Petro Diaz y Arias Diaz, 10.

Petrus Bazacus, 13.

Petrus Gudesteiz, arzobispo, 18.

Petrus Gudesteiz, marido de Marina Arias, 8.

Petrus M., qui notuit, 21.

Petrus Martin, notario y prelado en Gestoso, 24.

Petrus Martini, 23.- v. Petro Martini.

Petrus Micalu, 22.

Petrus Moogo, 24.

Petrus Petriz, fecit istam kartulam, 18.

Petrus Ruderici, 22.

Petrus Sancii, hermano de Hernandus/ Fernandus y Rodericus Sancii, 13.

Petrus, comite en Alva, Besaucos y Trava, 9.

Petrus, obispo de Lugo, 9.

Petrus, obispo de Orense, 17.

Quidus, obispo de Lugo, 12.

Ramiro Amiquiz, 8.

Ramiro, presbiter, 11.
Rodericus Sancii, hermano de Hernandus/ Fernandus y Petrus Sancii, 13.

Roderigus, comite en Sarria, 9.

Rodrigu, comes, hijo de Ovequiz, marido de Todda, 3.

Ruderico Menendi, 22.

Rudericus Petri, 22.

Rudericus Velasci, 22.

Ruy Garcia, don, merino mayor de Galicia, 24.

Ruy Garcia, merino en Limia, 24.

Ruy Meendez, hermano de Johan Meendez, hijo de Meen Muniz, 24.

S., abadesa de San Pedro Vilanova de Dozón, 23.

Sabarico, abuelo de Onoricus, Petro, Pelagio, Trodilli, Alosinda y Marina Froilaz, 6.

Sancia Muniz, mujer de Didacus Iohannis, hija de Marina Petriz, 1.

Sonegildo, marido de Ledegundia, hijo de Guntino y Aragunti, 2.

Stevao Pelaez, don, juez, 24.

Suario Petri, padre de Gontrode Suariz, 14.

Suario Petriz, marido de Tareixa/Tereixa Rodriquiz, 3.

Suario Petriz, padre de Petro Suariz, 12.

Suario, qui notuit, 5, 6 .

T arasia Moninz, domna, mujer de domno Fernando Odariz/Oariz, 17.

Tareiga, domna, posible abadesa de Vilanova de Dozón,18.

Tareixa Rodriquiz.- v. Tereixa Rodriquiz, 3.

Teomondo, abas notui, 2.

Terasia Arie, 21.

Tereisa Rodrigues, donna, abadesa del monasterio de San Pedro Vilanova de Dozón, 25.

Tereixa Rodriquiz, mujer de Suario Petriz, 3.

Tita Mirelliz, 2.

Toda Fernandiz, hermana de Aragunti Fernandiz, 13. 
Toda Petri, domna, abadesa de San Pedro Vilanova de Dozón, 19.

Todda, mujer del comes Rodrigo, hija de Gunzalviz, 3.

Todereo Elias, 2.

Trodilli Froilaz, hijo de Froilaz Gomez, nieto de Sabarico, hermano de Onoricus, Petro, Pelagio, Alosinda y Marina Froilaz, 6.

Tuda, domna, hermana de Maria Petriz, 18.

Uraca Arie, hermana de Peleagio y Maria Arie, hija de Arie Petri, 22.

Urraca Gomez, abadesa de San Pedro Vilanova de Dozón, 21.
Vasquo Fernandez, 25.

Veasco, padre de Gudesteo y Petro Veasquiz, 8.

Veremundo Menendiz, 11.

Veremundo, qui notuit, 4.

Vimara Gunzalviz, padre de Fernando Vimaraz, 3.

Vimara, notuit, 7.

Yldefonsus, notuit, confirmo, 16.

\section{ADVERTENCIA AL ÍNDICE DE TOPÓNIMOS}

Este índice está escrito en lengua gallega, pues el Nomenclátor de Galicia elaborado por los dictámenes de la Comisión de Toponimia y las normas dictadas por la Xunta de Galicia sólo contemplan como forma oficial la toponimia en dicha lengua, ignorando otras denominaciones.

Tanto los nombres oficiales actuales como sus variantes antiguas o no oficiales se ofrecen por orden alfabético.

El número o números que siguen a cada nombre indican el documento o documentos en el que se encuentra.

Los nombres oficiales actuales van en versalita; si el nombre antiguo coincide con la denominación oficial actual, se remite a él.

Los nombres que van en cursiva son topónimos localizados documentalmente, pero que no existen y no se identifican en la actualidad.

Las variantes antiguas $-\mathrm{y}$ las no oficiales-, se remiten siempre a su equivalente oficial actual, salvo las que no pudieron localizarse.

Los apellidos de personas que son topónimos sólo son localizados e identificados en aquellos casos que, o bien por los datos facilitados en los documentos donde aparecen, o por ser única la denominación existente en la zona geográfica a la que se refiere, hace precisa su ubicación.

«CUADERNOS DE ESTUDIOS GALLEGOS», Tomo L, Fascículo 116, Santiago 2003. 
A continuación del equivalente oficial actual -en versalita-, se expresan entre paréntesis las variantes aparecidas antiguas o no oficiales, junto con su localización.

\section{ÍNDICE TOPONÍMICO}

A beancos.- (Abiancos, Aviancus, terra de Aviancos).- Antiga xurisdicción que comprendería a zona dos actuais concellos de Melide, Arzua, Santiso e Toques, todos da prov. de A Coruña, xunto cos concellos limítrofes das prov. de Lugo e Pontevedra.

Abiancos, 9.- v. Abeancos.

Agelaz, villa, 16.- v. AXIAZ.

Agona, monte, 4. Probablemente situado entre os concellos de Silleda e Forcarei.

Agro Sex, 22.

AGROSAGRO, lugar de.- (Arboresagro, vila pernominata Arbosagro, Arvosagro).- Parroquia de Santo Estevo de Carboentes. Prov. de Pontevedra. Concello de Rodeiro.

AGUADA, Santa Baia.- Parroquia e lugar.(Aquaada). Prov. de Lugo. Concello de Carballedo.

Aliola, territorio y río, 3 .

Allenparte, casar d', 25.- v. DELAPARTE.

Alva, 9.- Antiga xurisdicción comprendida entre os ríos Miño, Barbantiño e Búbal, na prov. de Ourense e sur da de Lugo.

Amor, 21.- Parroquia de San Mamede de A Canda. Prov. de Ourense. Concello de Piñor. Semella que este lugar hoxe se identifica con VILARIÑO.

Aquaada, 12.- v. AGUADA.

Arbosagro, vila, 15.- v. AGROSAGRO.

ARCOS, lugar de.- (villa vocitada de Arcos).- Parroquia de Santa María de Grava. Prov. de Pontevedra. Concello de Silleda.

Arneci, alvei/ribulo, 16.- v. ARNEGO, (río). Arnego, 20.- v. ARNEGO, (Santiago).
Arnego, ribulo, 15.- v. ARNEGO, (río).

ARNEGO, río.- (alvei Arneci, ribulo Arneci, ribulo Arnego).- Afluente do Ulla, que discorre polos concellos de Rodeiro, Agolada e Lalín, na prov. de Pontevedra. ARNEGO, Santiago.- (Santo Iacobo de Arnego). Prov. de Pontevedra. Concello de Rodeiro.

ARNEGO, Santiago. Prov. de Pontevedra. Concello de Rodeiro.

Arnego, Santo Iacobo, 21.- v. ARNEGO.

Arvoresagro, 20.- v. AGROSAGRO.

Arvosagro, 20.- v. AGROSAGRO.

Arzos, villa, 4.- v. ARCOS.

Asma, 18.- (terra de Asma). Antiga xurisdicción na prov. de Lugo situada ó redor do concello de Chantada.

Asma, terra de, 13.- v. Asma.

Aural, monte, 11. Probablemente situado na fronteira dos concellos de Silleda e Lalín, ambolos dous na prov. de Pontevedra.

Auriense, 24.- v. OURENSE.

Aviancos, terra de, 13.- v. Abeancos.

Aviancus, territorio, 8.- v. Abeancos.

AXIAZ, lugar de.- (villa Agelaz).Parroquia de San Xulián de Ventosa. Prov. de Pontevedra. Concello de Agolada.

Badín, 21. En Paredes Seragita.

Banicili, 20.

Banios, 10.

Baran, 21.- v. BARRÁN.

BARCIA, A, lugar de.-(Varcena).- Parroquia de San Miguel de Siador. Prov. de Pontevedra. Concello de Silleda. 
BARCIA, lugar de.- (Varcena).- Parroquia de San Martiño de Fiestras. Prov. de Pontevedra. Concello de Silleda.

BARRÁN, San Xoán.- (Baran). Prov. de Ourense. Concello de Piñor.

Bertosindi, 2.

Besaucos, 9.

Bolo de Sendra, terra de, 25.- Antiga xurisdicción da Prov. de Ourense.

Bubal, terra de, 25.- v. Buvalense, territorio.

Buval, 18.- v. Buvalense, territorio.

Buvalense, territorio, 17.- (Buval, terra de Bubal).- Antiga xurisdicción no suroeste da prov. de Lugo e noroeste da de Ourense.

Cadrón, lugar de.- (Cadron).Parroquia de Santo Estevo de Cadrón. Prov. de Pontevedra. Concello de Lalín.

Cadrón, Martino Petri de, 19.- v. CADRÓN.

Camba, 15, 18.- (tera Kanba).- Antiga xurisdicción situada no que hoxe é o concello de Rodeiro, na prov. de Pontevedra.

Camba, Fernandus Diaz de, 19.- v. Camba.

Camba, Santa/Sancta Eulalia, 19.- v. SANTA BAIA DE CAMBA.

Campo, domne Eximie de, 23.

Captasolis, Santi Iacobi Apostoli, 7.- v. CATASÓS.

CARBALlEDA, Santa María.- (Santa Maria, Santa Maria de Carvaleda).Prov. de Ourense. Concello de Piñor.

Carballo Longo, 24.

CARBOENTES, Santo Estevo.- (San Estevo de Carvoentes, Sancti Stefani). Prov. de Pontevedra. Concello de Rodeiro.

CARRACEDO, Santiago.- (Sancto/Sancti Iacobo/Iacobi de Carrazedo). Prov. de Ourense. Concello de A Peroxa.

Carrazedo, Sancto/Sancti Iacobo/Iacobi, 17.- v. CARRACEDO.
Carvaleda, Santa Maria de, 21.- v. CARBALLEDA.

Castela, terra de, 25.- Antiga xurisdicción na Prov. de Ourense, tamén coñecida como O Chao de Castela.

CASTELA.- (Castella, Kastella).- Antigo reino da coroa de España.

Castella, 24.- v. CASTELA (reino).

CASTRO, O, San Salvador.- (Sancti Salvatoris de Honore).- Antigamente chamada San Salvador de la O. Prov. de Pontevedra. Concello de Dozón.

CATASÓS, Santiago.- (Santi Iacobi Apostoli Captasolis). Prov. de Pontevedra. Concello de Lalín.

CELEMÍN, lugar de.- (Cenamir).Parroquia de Santiago de Catasós. Prov. de Pontevedra. Concello de Lalín.

Cenamir, 7.- v. CELEMÍN.

CERCIO, Santiago. Prov. de Pontevedra. Concello de Lalín.

Circitu, monte, 7. Probablemente situado na parroquia de Santiago de CERCIO.

CÓRDOBA.- (Cordova).- Provincia, cidade e concello da rexión española de Andalucía.

Cordova, 24.- v. CÓRDOBA.

Coto, monte.- Posiblemente situado entre o concello lucense de Carballedo e o ourensano de A Peroxa, que hoxe non conserva o nome.

COVELOS, lugar de.- (aqua de Kovelo).Parroquia de Santa María de Dozón. Prov. de Pontevedra. Concello de Dozón.

Cuiarro, 12.- v. CUÑARRO.

Cunarro, 20.- v. CUÑARRO.

CUÑARRO do Cabo e do Medio, lugares de.- (Cuiarro, Mamuna de Cuiarro, Cunarro).- Parroquia de Santiago de Arnego. Prov. de Pontevedra. Concello de Rodeiro.

Deca, 18.- v. DEZA.

Decon, 22.- v. DOZÓN. 
Decon, flumine/rio, 1, 12.- Non localizado, aínda que probablemente discorra polos concellos de Dozón e Lalín, sendo un afluente do río Asneiro ou ben, o nome antigo deste río.

Decon, tera de, 25.- Antiga xurisdicción da prov. de Pontevedra.- v. DOZÓN.

Decon, territorio, 12.- v. DOZÓN.

DELAPARTE, lugar de.- (casar d'Allenparte).- Parroquia de San Miguel de Goyas. Prov. de Pontevedra. Concello de Lalín.

Deza, flubio, 11.- v. DEZA (río).

DEZA, río.- Discorre polos concellos de Silleda, Lalín e Vila de Cruces.

Deza, territorio, 4, 6.- v. DEZA.

DEZA.- (Deca, territorio Deza). Comarca e antiga xurisdicción na Prov. de Pontevedra situada entre o río Deza e o Arnego.

Dezon, 23.- v. DOZÓN, (mosteiro).

Dezon, territorio, 10.- v. DOZÓN.

Dezum, 22.- v. DOZÓN.

Dezum, Sancte Maria, 1.- v. DOZÓN, (Santa María).

DORRA, Santiago.- (Durra). Prov. de Lugo. Concello de Antas de Ulla.

DOZÓN, mosteiro de San Pedro de Vilanova de.- (Dezon, Sancti Petri de Villa Nova, Sancto Petro, Sanctum Petrum, Villa Nova, Villa Nova de Deçon, Ville Nove).- Lugar de O Mosteiro.- Parroquia de Santa María de Dozón. Prov. de Pontevedra. Concello de Dozón.

DOZÓN,Santa María.- (Sancta Maria, Sancte Maria de Dezum). Prov. de Pontevedra. Concello de Dozón.

DOZÓN.- Concello, parroquia (Santa María) e lugar.- (Decon, tera de Decon, territorio Dezon, Dezum). Prov. de Pontevedra. Concello de Dozón.

Durra, 18.- v. DORRA.

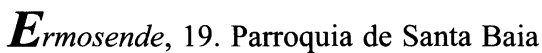
de Camba. Prov. de Pontevedra. Concello de Rodeiro.
Faton, 14.

Figeiru Odoarie, casar de, 21.- Parroquia de San Xoán de Barrán. Prov. de Ourense. Concello de Piñor.

Fontanelo, 6.

Fonte Bona, 6.- v. FONTEBOA.

FONTEBOA, lugar de.- (Fonte Bona).Parroquia de Santa Baia de Silleda. Prov. de Pontevedra. Concello de Silleda.

Frugulfi, kasale, 8.- Parroquia de Santo Estevo de Vilamoure. Prov. de Ourense. Concello de Punxín.

Galecia, 9, 17.- v. GALICIA.

GALICIA.- (Galecia, Galiza, Gallecia).Antigo reino da coroa de España; rexión histórica de España.

Galiza, 24.- v. GALICIA.

Gallecia, 13.- v. GALICIA.

Garavelus, Maria Petri, 22.

Geen, 24.- v. XAÉN.

Gestoso, 24.- v. XESTOSO.

GOIÁS, San Miguel de.- (San Miguell de Goyas). Prov. de Pontevedra. Concello de Lalín.

Goyas, San Miguell de, 25.- v. GOIÁS.

GRABA, Santa María.- (Grava). Prov. de Pontevedra. Concello de Silleda.

Grava, 4.- v. GRABA.

Guimaraes, vallo de, 10.

GURGUEIRO, San Miguel de.- (Sancti Michaelis de Lagenosa, Sancti Migahel de Lainosa). Prov. de Pontevedra. Concello de Agolada.

Honore, monte, 10. Probablemente situado no concello de Dozón, prov. de Pontevedra, que hoxe non conserva o nome.

Honore, Sancti Salvatoris de, 10.- v. CASTRO, O.

Insula, Sancti Migael de, monasterio, 13.

Jagan, 25.- v. XAXÁN. 
Kanba, tera., 15.- v. Camba.

Kastella, 9.- v. CASTELA (reino).

Kastro, vogabulo, 3.

Kavalaria, 20.- Parroquia de Santiago de Arnego. Prov. de Pontevedra. Concello de Rodeiro.

Kovelo, aqua de, 10.- v. COVELOS.

Lagenosa, Sancti Michaelis de, 13.- Antiga parroquia que pode corresponderse coa actual de San Miguel de GURGUEIRO, onde, ademáis, se atopa o lugar de LAXOSA.

Lageosa, 20.- v. LAXOSA.

Lainosa, Sancti Migahel de, 14. Antiga parroquia que pode corresponderse coa actual de San Miguel de GURGUEIRO, onde, ademáis, se atopa o lugar de LAXOSA.

Laquozos, 10.

LARO, lugar de.- Parroquia de San Salvador de Laro. Prov. de Pontevedra. Concello de Silleda.

Laro, monte, 5.- Elevación de terreo localizada en LARO.

LAXOSA, lugar de.- (Antiga parroquia de San Miguel: Sancti Michaelis de Lagenosa).- Parroquia de San Miguel de Gurgueiro. Prov. de Pontevedra. Concello de Agolada.

LAXOSA, lugar de.-(Lageosa).- Parroquia de San Miguel de Gurgueiro. Prov. de Pontevedra. Concello de Agolada.

LEBOZÁN, Santiago de.- (Sancti Iacobi). Prov. de Pontevedra. Concello de Lalín.

Legione, 9.- v. LEÓN.

Lemus, 18.- v. TERRA DE LEMOS.

Lene, monte, $3,8$.

Leon, 24.- v. LEÓN.

LEÓN.- (Legione, Leon, Leone).- Antigo reino da coroa de España. Hoxe cidade e concello da Comunidade Autónoma de Castela e León.

Leone, 17.- v. LEÓN.

Limia, 24.- v. LIMIA, A.
LIMIA, A.- (Limia).- Comarca do sur da prov. de Ourense ó redor dos concellos de Xinzo de Limia e Trasmiras.

Linares, 9.- v. LIÑARES.

LIÑARES, lugar de.- (Linares).- Parroquia de_Santiago de Liñares. Prov. de A Coruña. Concello de Santiso.

Lucenca, arogio, 6. Probablemente sexa un pequeno afluente do río TOXA.

Lucense ecclesia, 17.- v. LUGO.

Lucense sedis, 9.- v. LUGO.

LUGO.- (lucense ecclesia, lucense sedis).Provincia, cidade, bispado e concello. Prov. de Lugo. Concello de Lugo.

Malarici, 2.

Mamona, monte, 12. Probablemente situado no concello de Dozón, preto do de Rodeiro, non localizado.

Mamuna de Cuiarro, 1.- v. CUÑARRO.

MARÍN, lugar de.- (Merlaim).- Parroquia de San Martiño de Fiestras. Prov. de Pontevedra. Concello de Silleda.

Maurigaes, 20.- v. MOURIGÁS.

Megimenci, 20.- v. MEIXOMÍN.

Meisomemenz, 4.- v. Meisomenz.

Meisomenz, 4.

Meitiriz, villa, 11.

MEIXOMÍN, lugar de.- (Megimenci).Parroquia de San Lourenzo de Moimenta. Prov. de Pontevedra. Concello de Lalín.

Mera, arrogio, 11. Probablemente sexa un pequeno afluente do río Deza, non localizado hoxe.

Merlaim, 6.- v. MARÍN.

Mineo, rivulo, 17.- v. MIÑO (río).

MIÑO, río.- (rivulo Mineo).- Principal río de Galicia, que nace no concello de Meira da prov. de Lugo e desemboca no océano Atlántico.

Moe, 22.- v. MOI.

MOI, lugar de.- (Moe).- Parroquia de Santiago de Saa. Prov. de Pontevedra. Concello de Dozón.

Monte Roso, Arias Petriz de, 17.- v. MONTERROSO. 
Monte Roso, princeps de.- v. MONTERROSO

Monteroso, 9.- v. MONTERROSO.

Monterroso, 13.- v. MONTERROSO.

MONTERROSO.- (Monte Roso).Concello e vila. Prov. de Lugo. Concello de Monterroso.

Montes, 18.- Antiga xurisdicción da prov. de Pontevedra.

MOURIGÁS, lugar de.- (Maurigaes).Parroquia de Santiago de Arnego. Prov. de Pontevedra. Concello de Rodeiro.

Munim, 23.- Antes este lugar pertencía á parroquia de Santiago de LEBOZÁN, no concello de Lalín.- v. MUNÍN.

MUNÍN, lugar de.- (Munim).- Parroquia de San Pedro de Espiñeira. Prov. de Ourense. Concello de OIrixo.

MURCIA.- (Murza).- Rexión histórica de España. Hoxe provincia, cidade e concello da rexión de Murcia.

Murza, 24.- v. MURCIA.

$\mathbf{N}_{\text {avego, monte, 15.- Posiblemente situa- }}$ do na prov. de Pontevedra entre os concellos de Rodeiro e Dozón, que hoxe non conserva o nome.

$\boldsymbol{O}_{\text {doarie, Figeiru, casar de, 21.- Parroquia }}$ de San Xoán de Barrán. Prov. de Ourense. Concello de Piñor.

OLEIROS, San Miguel.- (Sancti Michaelis). Prov. de Pontevedra. Concello de Silleda.

Oriense, 17.- v. OURENSE.

Orrea, monasterio de, 13. Antigo mosteiro de monxas benedictinas chamado «de San Andrés de Orrea», situado no concello de A Golada.- v. ÓRREA.

ÓRREA. Lugar e parroquia de Santo André.- (Orrea).- Parroquia de Santo André de Órrea. Prov. de Pontevedra. Concello de A Golada.

OURENSE.- Provincia, cidade, bispado e concello.- (Auriense, Oriense). Prov. de Ourense. Concello de Ourense.
Palaciis de Monte, 12.- Parroquia de Santa Baia de Aguada. Prov. de Lugo. Concello de Carballedo.

Palatios, 14.

Paredes Seragita, 21.- v. PAREDES.

PAREDES, lugar de.- (Paredes Seragita).Parroquia de Santa María do Desterro de A Corna. Prov. de Ourense. Concello de Piñor.

Pena Lada, 16

Pena Nigra, 10.

Pena Vitale, 6.

PEREDA, Santa Baia.- (Perera). Prov. de Ourense. Concello de San Cristovo de Cea.

Perera, 20.- v. PEREDA.

Petra Erecta, 10.

Pinol, 19.- v. PIÑOR.

PIÑOR. Lugar e concello.- (Pinol).Parroquia de San Xoán de Barrán. Prov. de Ourense. Concello de Piñor.

PONTE, San Miguel.- (Sancti Michaelis). Prov. de Pontevedra. Concello de Silleda.

Portella, Sancto Stephani de, 14.- Antiga parroquia que parece corresponderse coa actual de Santo Estevo de SALTO, O.

Pulgam, mamua de, 10.

Qualamis, 5.- Antiga vila de reguengo, posiblemente situada na prov. de Pontevedra.

QUINTÁ, lugar de.- (Quintana).Parroquia de Santa María de Dozón. Prov. de Pontevedra. Concello de Dozón.

Quintana, 1, 12.- v. QUINTÁ.

$\boldsymbol{R}$ aniola, arrogio, 8. Pequeno afluente, non localizado, do río Miño.

Riba de Mino, 24.- Antiga xurisdicción da Prov. de Lugo.

RIBADULLA, lugar de.- Parroquia de Santiago de Dorra. Prov. de Lugo. Concello de Antas de Ulla. 
RÍO, lugar de.- (villa Riulo).- Parroquia de San Xulián de Ventosa. Prov. de Pontevedra. Concello de Agolada.

Ripa Ulia, 18.- Terra situada ó redor da hoxe denominada comarca de A Ulloa, entre as provincias de A Coruña, Lugo e Pontevedra.

Ripa Ulia, Sancti Felicis, 13.- Antiga parroquia, hoxe desaparecida, que pode corresponderse co actual lugar de RIBADULLA.

Ripe Ulie, Sancti Felizi, 14.- Antiga parroquia, hoxe desaparecida, que pode corresponderse co actual lugar de RIBADULLA

Riulo, villa, 16.- v. RÍO.

Rivulo Seco, 17.

Saa, Sancti Iacobi, 22.- v. SAA.

SAA, Santiago.- (Sancto Iacobi de Saa). Prov. de Pontevedra. Concello de Dozón.

Salnes, Fernando Fernandez de, 17.- v. SALNÉS, O.

SALNÉS, O.- (Salnes).- Península e comarca que comprende varios concellos do oeste da prov. de Pontevedra, ó redor de Cambados, Ribadumia e O Grove.

SALTO, O, Santo Estevo de.- (Sancti Stefanus, Sancto Stephani de Portella). Prov. de Pontevedra. Concello de Rodeiro.

Sancta Eulalia, 6.- v. SILLEDA.

Sancta Maria, 12.- v. DOZÓN,(Santa María).

Sancti Antonini, 9.- Posible monasterio, hoy desaparecido.

Sancti Iacobi, 23.- v. LEBOZÁN.

Sancti Iacobi, 9.- Igrexa en territorio de Aveancos.

Sancti Iacobi, obispado de, 9.- v. SANTIAGO DE COMPOSTELA.

Sancti Michaelis, 11.- v. OLEIROS e PONTE.

Sancti Petri, 2.
Sancti Stefani, 15.- v. CARBOENTES.

Sancti Stefanus, 20.- v. SALTO, O.

Sancti Stephani, 8.- v. VILAMOURE, (Santo Estevo).

Sancto Iuliano, 16.- v. VENTOSA.

Sancto Petro, 19.- v. DOZÓN, (mosteiro).

Sanctum Petrum, 21.- v. DOZÓN, (mosteiro).

SANTA BAIA DE CAMBA, Santa Baia.(Santa/Sancta Eulalia de Camba). Prov. de Pontevedra. Concello de Rodeiro.

Santa Maria, 21.- v. CARBALLEDA.

SANTIAGO DE COMPOSTELA.- (Sancti Iacobi).- Cidade e concello. Prov. de A Coruña. Concello de Santiago de Compostela.

Saria, 9.- v. SARRIA.

Sarria, 18.- v. SARRIA.

SARRIA.- (Saria). Vila e concello. Prov. de Lugo. Concello de Sarria.

Seragita, Paredes, 21.- v. PAREDES.

SEVILLA.- (Sivilla).- Provincia, cidade e concello da rexión española de Andalucía.

SILLEDA, Santa Baia.- (Sancta Eulalia).Prov. de Pontevedra. Concello de Silleda.

Sivilla, 24.- v. SEVILLA

Tabeirós terra de MONTES.(Tavairolos, Taveirolas).- Comarca do norte da prov. de Pontevedra, ó redor dos concellos de A Estrada e Forcarei.

Tavairolos, 17.- v. TABEIRÓS TERRA DE MONTES.

Taveirolas, 18.- v. TABEIRÓS TERRA DE MONTES

TERRA DE LEMOS.- (Lemus).- Comarca do sur da prov. de Lugo, que comprende principalmente os concellos de Monforte de Lemos e Sober.

Tiduledu, 16.

Toen, 24.- v. TOÉN.

TOÉN.- (Toen).- Vila e concello. Prov. de Ourense. Concello de Toén. 
Toga, ribulo, 6.- v. TOXA (río).

Togia, arogio/ribulo, 4, 5.- v. TOXA (río).

Togia, villa, 5.- v. TOXA (lugar).

Toledo, 24.- v. TOLEDO.

TOLEDO.- Provincia, cidade e concello pertencente a rexión histórica de España de Castela-a-Nova.

TOXA, lugar de.- (villa Togia).- Parroquia de Santa Baia de Silleda. Prov. de Pontevedra. Concello de Silleda.

TOXA, río.- (ribulo Toga, arogio Togia, ribulo Togia).- Discorre polos concellos de Silleda e Vilar de Cruces.

Trava, 9. Antigo territorio na prov. de A Coruña, correspondente coa zona da parroquia de Santiago de Traba, no concello de Laxe.

Valle Scuro, 10

Varazon, arrogio, 8. Pequeno afluente, non localizado, do río Miño.

Varcena, 6.- v. BARCIA e BARCIA, A.

Ventosa, 13.- v. VENTOSA.

Ventosa, 20.- v. VENTOSA.

VENTOSA, San Xulián.- (Ventosa, Sancto Iuliano, teritorio de Ventossa). Prov. de Pontevedra. Concello de Agolada.

Ventossa, teritorio, 16.- Antiga xurisdicción que podería situarse ó redor da actual parroquia de San Xulián de VENTOSA.
VILAMOURE, lugar de.- (Villa Mauri).Parroquia de Santo Estevo de Vilamoure. Prov. de Ourense. Concello de Punxín.

VILAMOURE, Santo Estevo.- (Sancti Stephani). Prov. de Ourense. Concello de Punxín.

VILARIÑO, lugar de.- (Amor).- Parroquia de San Mamede de A Canda. Prov. de Ourense. Concello de Piñor.

Villa Coba, 22.

Villa Mauri, 8.- v. VILAMOURE, lugar de.

Villa Nova de Deçon, 25.- v. DOZÓN, (mosteiro).

Villa Nova, 18, 19, 24.- v. DOZÓN, (mosteiro).

Villa Nova, Sancti Petri de, 13.- v. DOZÓN, (mosteiro).

Villanova, Sancto Petro de, 19.- v. DOZÓN, (mosteiro).

Ville Nove, 21.- v. DOZÓN, (mosteiro).

XAÉn.- (Geen).- Provincia, cidade e concello da rexión española de Andalucía. Nome oficial «Jaén».

XAXÁN, lugar de.- (Jagan).- Parroquia de Santa María da Saleta de Xaxán. Prov. de Pontevedra. Concello de Lalín.

XESTOSO, Santa María.- (Gestoso). Prov. de Pontevedra. Concello de Silleda.

\section{BIBLIOGRAFÍA}

Decreto 332/1996, do 26 de xullo, polo que se aproba o nomenclátor correspondente ás entidades de poboación da provincia de Ourense, Diario Oficial de Galicia, Santiago, 29 de Agosto de 1996.

Decreto 219/1998, do 2 de xullo, polo que se aproba o nomenclátor correspondente ás entidades de poboación da provincia de Pontevedra, Diario Oficial de Galicia, Santiago, 28 de Julio de 1998. 
Decreto 6/2000, do 7 de xaneiro, polo que se aproba o nomenclátor correspondente ás entidades de poboación da provincia de Lugo, Diario Oficial de Galicia, Santiago, 25 de Enero de 2000.

Decreto 189/2003, do 6 de febreiro, polo que se aproba o nomenclátor correspondente ás entidades de poboación da Provincia da Coruña, Diario Oficial de Galicia, Santiago, 25 de marzo de 2003.

DURO PEÑA, E., El monasterio de San Pedro de Vilanova de Dozón, Archivos Leoneses, 43, año XXII, (enero-junio 1968), pp. 7-62.

FERNÁNDEZ DE VIANA Y VIEITES, J. I., Problemas en torno al monasterio de San Pedro de Dozón, CEG, $X X X V$, (1984-85), pp. 117-123.

GARCÍA M. COLOMBÁS, M. B., Las señoras de San Payo. Historia de las Monjas Benedictinas de San Pelayo de Antealtares, Santiago de Compostela, Caja de Ahorros de Galicia, 1980.

GRAN ENCICLOPEDIA GALLEGA, T. 30, p. 86.

LUCAS ÁLVAREZ, M., «Paleografía gallega. Estado de la cuestión», Anuario de estudios medievales, 21, (1991) pp. 419-470.

LUCAS ÁLVAREZ, M., «Para unas normas complementarias de transcripción de documentos en gallego», CEG., XII, (1949), pp. 95-110.

MIRALBES BEDERA, R; TORRES LUNA, Mª . P. de; RODRÍGUEZ MARTÍNEZ-CONDE, R., Mapa de límites de las parroquias de Galicia, Santiago, Universidad, 1979.

Nomenclátor de Galicia. [En línea]. Disponible en http.//xunta.es./ nomenclator/index.htm (Consulta de fecha 7-abril-2003).

PERALTA, T., Fundación, antigüedad y progresos del imperial monasterio de Nuestra Señora de Osera, de la Orden del Císter, Madrid, 1677. 
PÉREZ RODRÍGUEZ, F. J., Benedictinos e cistercienses: un reconto dos mosteiros galegos a finais do século XII, Actas II Congreso Internacional sobre el Císter en Galicia y Portugal, Ourense, 1998, pp. 695724.

PORTELA, Ma J.; GARRIDO, M.; ROMANÍ, M., Repertorio para las escripturas del Archivo Bajo. Catálogo del Archivo Monacal de Oseira en 1629, [Santiago], Tórculo, D.L. 1993.

PRECEDO LEDO, A.; SANCHO COMÍNS, J. (dirs.), Atlas de Galicia, Vol. 1, [Santiago], Sociedade para o Desenvolvemento Comarcal de Galicia, 2001.

ROMANÍ MARTÍNEZ, M., Colección Diplomática do Mosteiro Cisterciense de Sta. María de Oseira (Ourense), 1025-1310, 2 vols., Santiago, Tórculo, 1989.

ROMANÍ MARTÍNEZ, M., El Monasterio Cisterciense de Santa María de Oseira (Ourense), (1137-1310). Estudio Histórico, Santiago, Universidad, 1989.

ROMANÍ MARTÍNEZ, M.; PORTELA, Mª J.; RODRÍGUEZ SUAREZ, $\mathrm{M}^{\mathrm{a}}$ del P.; VÁZQUEZ BERTOMEU, M., Colección Diplomática do Mosteiro Cisterciense de Sta. María de Oseira (Ourense), 1310-1399, Vol. III, Santiago, Tórculo, 1993.

«CUADERNOS DE ESTUDIOS GALLEGOS», Tomo L, Fascículo 116, Santiago 2003. 